\title{
Circuit
}

Musiques contemporaines

\section{Îles de la Nuit}

Parcours dans l'œuvre pour quatuor à cordes de R. Murray

Schafer

\section{"Îles de la nuit": an Overview of R. Murray Schafer's String Quartets}

\section{Jean Portugais et Olga Ranzenhofer}

Volume 11, numéro 2, 2000

Le quatuor à cordes selon Schafer

URI : https://id.erudit.org/iderudit/004688ar

DOI : https://doi.org/10.7202/004688ar

Aller au sommaire du numéro

Éditeur(s)

Les Presses de l'Université de Montréal

ISSN

1183-1693 (imprimé)

1488-9692 (numérique)

Découvrir la revue

Citer cet article

Portugais, J. \& Ranzenhofer, O. (2000). Îles de la Nuit : parcours dans l'œuvre pour quatuor à cordes de R. Murray Schafer. Circuit, 11(2), 15-54.

https://doi.org/10.7202/004688ar
Résumé de l'article

Ce texte propose un parcours dans le corpus des sept quatuors de Schafer à travers une quarantaine d'exemples musicaux. Le parcours est développé de manière à faire apparaître à la fois l'unité du cycle et la caractérisation propre à chaque oeuvre, dans un effort de situer ce corpus dans un cadre de lecture à la fois poétique et philosophique. En retraçant quelques éléments fondamentaux pour chaque quatuor, le texte propose une suite de repères musicaux et esthétiques qui constituent, selon les auteurs, autant d'entrées possibles dans les quatuors à cordes de Murray Schafer. 


\section{îles de la Nuit \\ Parcours dans l'œuvre pour quatuor à cordes de R. Murray Schafer ${ }^{1}$}

Jean Portugais et Olga Ranzenhofer

\begin{abstract}
Murray Schafer is a true Renaissance man. Not only is he a superb modern composer and a leading Anti-Romantic, like Schönberg he is an artist who creates paintings that are like the vague dream of a tapestry from a mysterious world. As Schafer will tell you himself, he is a romantic at heart, but it is rare to find so powerful an intelligence at work in contemporary music. Always aware that the self is relative, his work penetrates from past to future, following a rich vein of ore deep into the present. As he does this, Schafer's music soars from the mundane world into the realm of dreams.
\end{abstract}

TORU TAKEMITSU

Îles de la Nuit. Les quatuors à cordes de Murray Schafer sont des musiques nocturnes, pleines de murmures et de confidences, délibérément romantiques et expressives et qui, malgré qu'elles intègrent de nombreux acquis de l'écriture musicale du Xxe siècle, vont à contre-courant du modernisme et du formalisme.

Nous proposons ici un parcours à travers le corpus des sept quatuors de Schafer en nous appuyant sur notre expérience et notre pratique assidue de ces œuvres depuis plusieurs années, et aussi sur nos références personnelles. En donnant à voir plusieurs extraits des partitions de Schafer, nous avons voulu livrer au lecteur quelques-unes des richesses musicales de ces quatuors, mais en les présentant dans un cadre qui reflète notre compréhension et notre conception de ces œuvres. Comme nous avons peu d'appétit pour les analyses doctrinales et sévères, nous avons préféré tenter de caractériser chaque quatuor et le cycle tout entier en évoquant du mieux que nous pouvions la fascination que ces œuvres ont exercée sur nous. Ainsi, le caractère cyclique de l'ensemble de ces quatuors ne sera pas démontré suivant les nécessités du discours déductif et ostentatoire, mais si notre parcours est réussi, ce caractère cyclique devrait selon nous être sensible à travers les références musicales, poétiques et philosophiques au sein desquelles nous avons choisi de placer ces œuvres. Le présent texte pourrait ainsi devenir un
1. Le titre est une allusion à notre grand poète disparu Alain Grandbois 11900 1975), qui aurait eu cent ans cette année, et à son recueil intitulé Îles de la Nuit (1990, t. 1, p. 102-143). 
instrument pour «entrer» dans ces quatuors, pour pénétrer dans l'univers nocturne de ces musiques de Schafer. Nous avons simplement souhaité fournir des repères musicaux et rendre vivant un éclairage singulier sur ces œuvres, sans pourtant ne jamais supposer une existence autonome au texte que l'on va lire. Au contraire, pensons-nous, c'est par une écoute répétée des quatuors que celui qui veut en apprécier toutes les qualités pourra vraiment le faire ${ }^{2}$.

Plusieurs motifs justifient notre choix de présenter un tel type de parcours. Une première motivation est liée au contenu musical lui-même : il y a des musiques sur lesquelles l'écrit analytique est la principale prise possible, car l'écoute ne rend souvent pas ses vertus ${ }^{3}$, et il y a des musiques pour lesquelles l'écrit paraît nécessairement mineur, voire inutile puisque l'écoute persuade en elle-même ${ }^{4}$. Nous rangeons les quatuors de Schafer dans cette deuxième catégorie. Une autre motivation est d'ordre esthétique : le caractère romantique et narratif des quatuors de Schafer nous semblait appeler de lui-même un travail de ce type, plus évocateur que démonstratif. Enfin, une autre motivation à ce type de parcours aura été, pour le présent texte, la recherche d'un climat qui puisse renvoyer à celui des quatuors eux-mêmes. De telles motivations sont à l'opposé de toute volonté de rendre compte ou de cataloguer des œuvres selon des typologies musicologiques, car notre désir aura été plutôt de contribuer de manière personnelle à créer des conditions de réception favorables à l'écoute des quatuors de Schafer.

En offrant un parcours chronologique, nous ne négligeons pas, cependant, les multiples liens qui unissent ces œuvres les unes aux autres. Ces liens vont bien audelà des déplacements scéniques qu'on retrouve dans plusieurs quatuors et qui ne constituent en quelque sorte que la partie visible de l'iceberg. Nous avons été attentifs aux correspondances multiples qui se tissent entre ces œuvres. Toutefois, nous ne voulions ni ne pouvions les souligner toutes. C'est, croyons-nous, le propre des corpus d'une certaine importance que de ne livrer leur substance qu'au moyen d'une fréquentation assidue et prolongée.
2. Deux enregistrements sont disponibles: Quatuors nos 7 à 5 par le Quatuor Orford (Centredisques CMC, CD 39/4090) et les Quatuors nos 1 à 7 par le Quatuor Molinari (ATMA classique, ACD 2 2188/89).

3. En témoignent ces deux célèbres propos de Xenakis et de Messiaen. Xenakis, dans son article sur la crise de la musique sérielle, publié à l'origine dans Gravesaner Blätter en 1955, explique que «la polyphonie linéaire se détruit d'elle-même par sa complexité actuelle», pourtant séduisante sur papier (Xenakis, 1971, p. 120). Olivier Messiaen confiait pour sa part à Claude Samuel que selon lui, la musique de Xenakis la plus complexe, fondée sur des calculs savantissimes, s'écoutait pourtant sans besoin de se référer aux calculs mathématiques et que seuls comptaient l'expérience esthétique et le caractère tellurique des sons entendus (Samuel, 1967).

4. À cet égard, voici deux exemples frappants d'écrits sur la musique qui appartiennent selon nous à ce second type : le livre sur Mahler de Theodor Adorno (1976) et celui sur les quatuors de Beethoven par Joseph Kerman (1982).

\section{Premier Quatuor (1970) ${ }^{5}$}

\author{
nuit qui fais tant implorer l'aube \\ nuit de grâce, tombe
}

BECKETT

Le début puissant et dur du Premier Quatuor n'annonce pas le ton de l'ensemble du corpus, tant s'en faut (fig. 1).
5. Composé à Vancouver et à Toronto, d'avril à mai 1970, le Premier Quatuor résulte d'une commande passée par le Quatuor Purcell qui a créé l'œuvre à Vancouver le 6 juillet 1970. Le Premier Quatuor a remporté le prix Arthur-Honegger en 1970 . 
Figure $1^{\circ}$

Premier Quatuor, page 3, $4^{\mathrm{e}}$ système

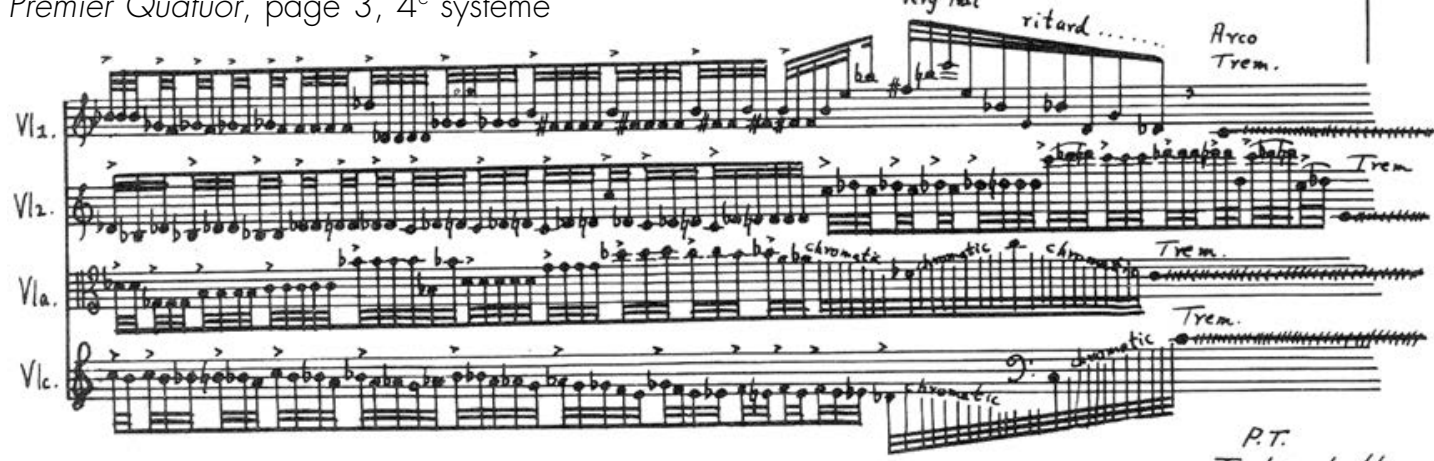

Independently

("C"to be sustained)

Cette "ouverture tragique » est un magma sonore inouï qui dit d'entrée de jeu que Schafer refuse le caractère dialectique du quatuor à cordes ${ }^{7}$. Pendant ces quatre minutes insoutenables d'intensité, de force et de violence, les musiciens cherchent sensiblement à s'émanciper de cet amalgame, ils cherchent à se libérer de l'emprise du groupe au moyen d'un jeu à la fois contrôlé et libre avec la métrique. De simples indications de minutage remplacent les barres de mesure (fig. 1).

Dès l'apaisement commencé, le ton lyrique et méditatif si typique de l'ensemble de l'œuvre est posé : séquences microtonales en seizièmes de ton, arabesques et broderies, jeux rythmiques en col legno battuto, sforzandi, timbres variés, glissandi poétiques et unissons intenses. C'est que si le vocabulaire et la syntaxe sont modernes, le sens de la musique de Schafer est pourtant délibérément romantique, narratif et expressif.

Plusieurs épisodes de ce Premier Quatuor sont déjà typiques des musiques de nuit qui vont hanter tout le corpus, par exemple celui-ci, calme et statique (fig. 2).

Figure 2

Premier Quatuor, page 9, $2^{e}$ système

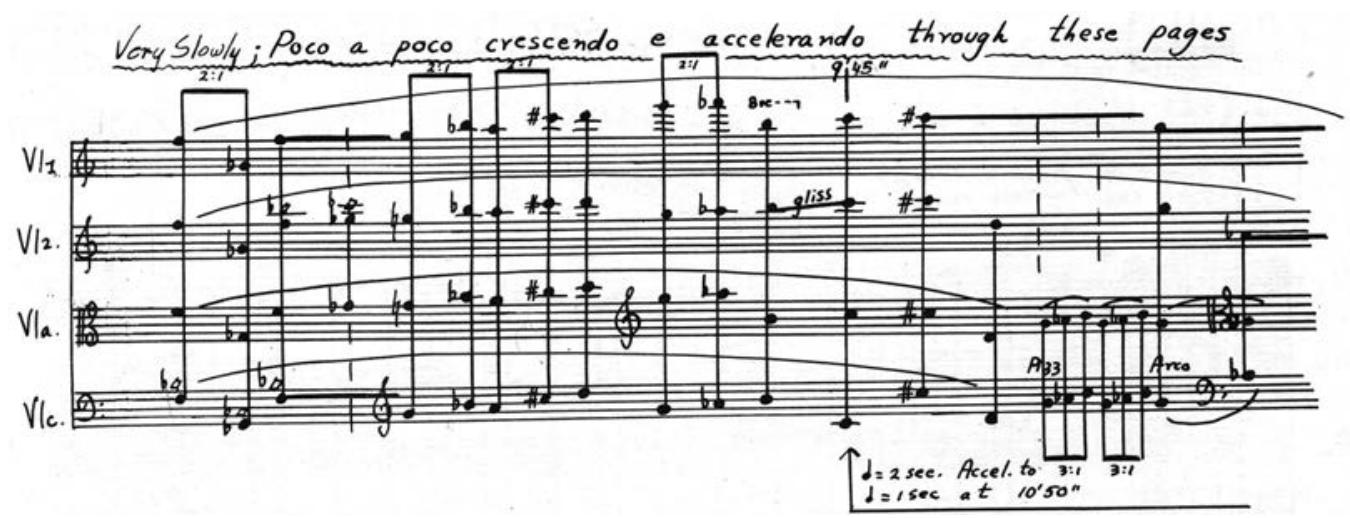

6. Cette figure et toutes les suivantes sont tirées des partitions des quatuors à cordes de Schafer, dont la référence complète se trouve en bibliographie. La reproduction du Premier Quatuor a été autorisée par l'édition Universal, tandis que celle des Deuxième au Septième Quatuors l'a été par les éditions Arcana.

7. Voir la conférence de Schafer à ce sujet, où il affirme que Beethoven a épuisé ce potentiel dialectique du quatuor. 
Des voix intimes chantent. Ailleurs, des harmoniques artificielles dans le suraigu donnent à certains épisodes un ton de mystère, de supranaturel, de secret. Cependant, les inquiétudes, voire les angoisses, ne seront pas absentes de cette première «nuit» de cordes (fig. 3).

Figure 3

Premier Quatuor, page 13, $1^{\text {er }}$ système

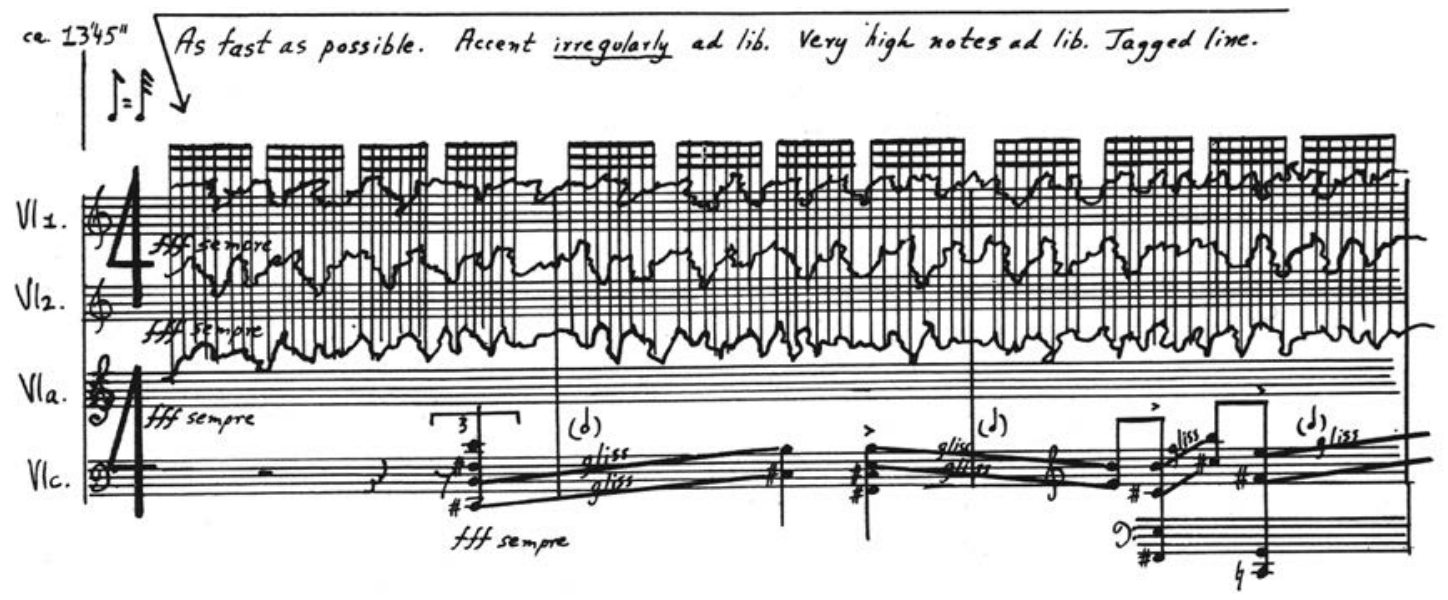

L'opposition entre les moments violents et les moments de méditation s'installe, tout comme celle entre les jeux rythmiques et la substance lyrique. Tout fait trace. Tout s'ensuit de même, avec la même liberté d'invention, le même souffle romantique. Dualité ? Sans doute. Jeux de masques et de doubles déjà, comme les Florestan et Eusebius de Schumann, toujours complémentaires et antagonistes, comme les deux visages de Janus aussi.

La récapitulation, en forme de clichés photographiques des différents épisodes du quatuor, cite de minuscules fragments de cette fascinante mosaïque (fig. 4).

Les allusions sont murmures, souvenirs et sorties du territoire visité. On ne cessera plus désormais de revenir sur nos pas et chaque quatuor, chaque "île de Nuit», pourra être reconnu comme un membre de la famille avec ses motifs communs et ses nombreux renvois. Chaque quatuor sera à la fois élément de l'archipel et entité irréductible. 
Figure 4

Premier Quatuor, page $15,3^{e}$ et $4^{e}$ systèmes

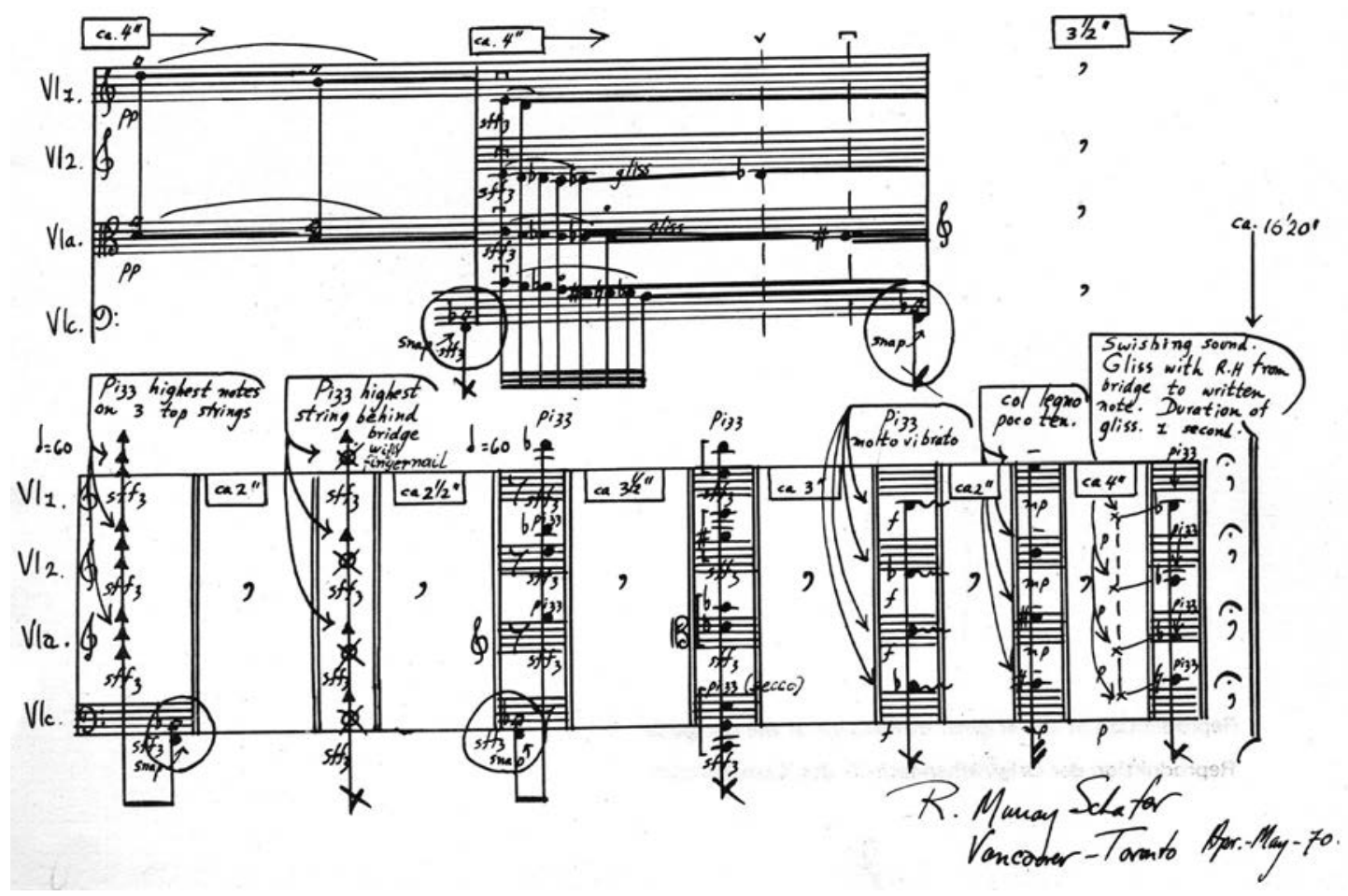

\section{Deuxième Quatuor: Waves (1976) ${ }^{8}$}

La mer. Le souffle du vent. Les vagues. Les ressacs. Îles du large, mystérieuses et sombres. Dès les premiers instants du second quatuor, l'auditeur est frappé par la création d'un si grand espace sonore au moyen de simples cellules conjointes jouées pianissimo sul tasto.

De nouveau donc, un univers romantique. Waves dépeint le rythme du bris et du ressac des vagues des océans Atlantique et Pacifique des côtes canadiennes. Le traitement est cependant issu des recherches du World Soundscape Project (1973), au sein duquel Schafer étudiait les phénomènes acoustiques de l'environnement naturel et urbain. Ces recherches ont montré que le rythme des vagues est toujours asymétrique et que le temps écoulé entre chacune d'elles se situe presque toujours entre six et onze secondes. La structure et le rythme de ce Deuxième Quatuor sont basés sur ce temps marin. Comme le rythme naturel des vagues, ce
8. Le Deuxième Quatuor a été composé à Monteagle Valley, en Ontario, de janvier à octobre 1976. II fut créé par le Quatuor Purcell à Vancouver, le 24 novembre 1976, et obtint le prix Jules-Léger pour la nouvelle musique de chambre en 1978. 
Quatuor se déroule en cycles successifs de six à onze secondes. Le Deuxième Quatuor s'ouvre ainsi en faisant dérouler des vagues de 11 secondes, puis de 10 secondes, puis successivement de $9,8,7,6,6,7,8,9,10,11$ secondes... Les structures en arche, si chères à Bartók et à Berg ${ }^{9}$, sont ici travaillées à l'échelle des événements sonores eux-mêmes. Schafer libère sa musique des contraintes temporelles des mouvements et des mesures, conçus comme des blocs positionnés les uns par rapport aux autres, pour rejoindre plutôt le rythme naturel de la mer tel que ses recherches lui ont permis de l'appréhender.

Évitant donc le piège facile du tableau descriptif, Schafer structure son œuvre au moyen de couches sonores successives: montées, descentes, répétitions, variations et retours à des points de focalisation repérables. Tout cela avec une extrême ductilité des voix et un traitement continuellement souple du matériau de base. Une des cellules génératrices qui forme les périodes est fa dièse - mi bémol - ré (voir fig. 5). Ces intervalles conjoints suggèrent aisément la fluidité; cela rappelle aussi la mer qui tangue doucement.

Ces cellules de base seront variées continuellement, avec une richesse éloquente sur le plan des textures et des tempi. La partition abonde en indications de changement de vitesse d'exécution: slow down, speed up, same tempo, gradually speed up to croche $=160$, gradually lengthen middle note. Même les rythmes subissent des transformations à l'intérieur d'une même cellule de trois ou quatre notes (fig. 5).

Figure 5

Deuxième Quatuor, page 6, $3^{e}$ système

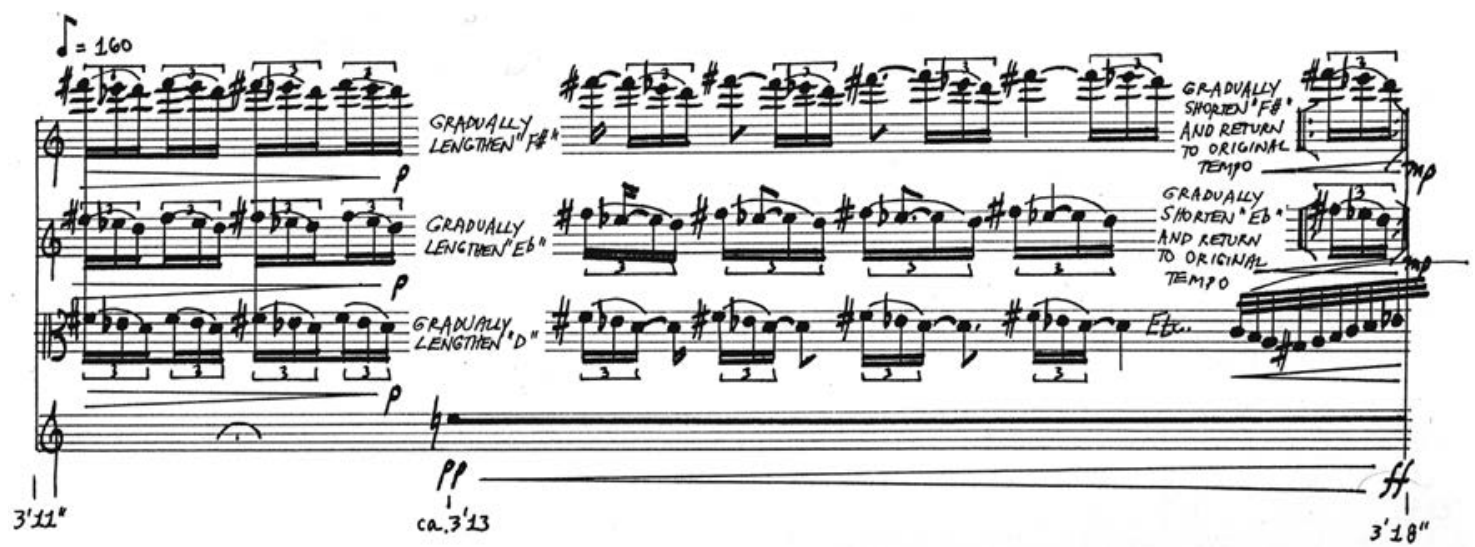

Schafer demande aux musiciens d'allonger graduellement une note et ensuite de la raccourcir pour revenir à la valeur initiale (fig. 5). Ces éléments de technique d'écriture permettent d'établir une perpétuelle fuite vers l'avant, une instabilité qui se joue sur d'infinitésimaux points de discontinuité. Le résultat, impressionniste et raffiné, peut pourtant s'apprécier en économie complète de l'analyse.

9. Chez Alban Berg, la Suite lyrique adopte une structure en double arche (Jameux, 1980). Chez Bartók, on retrouve une structure en arche de la forme ABCBA pour les mouvements du Quatrième Quatuor de 1928 (Halbreich, 1986). 
Mais il y a plus. Les microvariations des vagues successives seront variées elles-mêmes à des niveaux de plus en plus élevés d'intensité. La tessiture s'élargit, les cellules deviennent de plus en plus amples jusqu'au déchaînement des vagues de haute mer (fig. 6).

Figure 6

Deuxième Quatuor, page 16, $1^{\text {er }}$ système

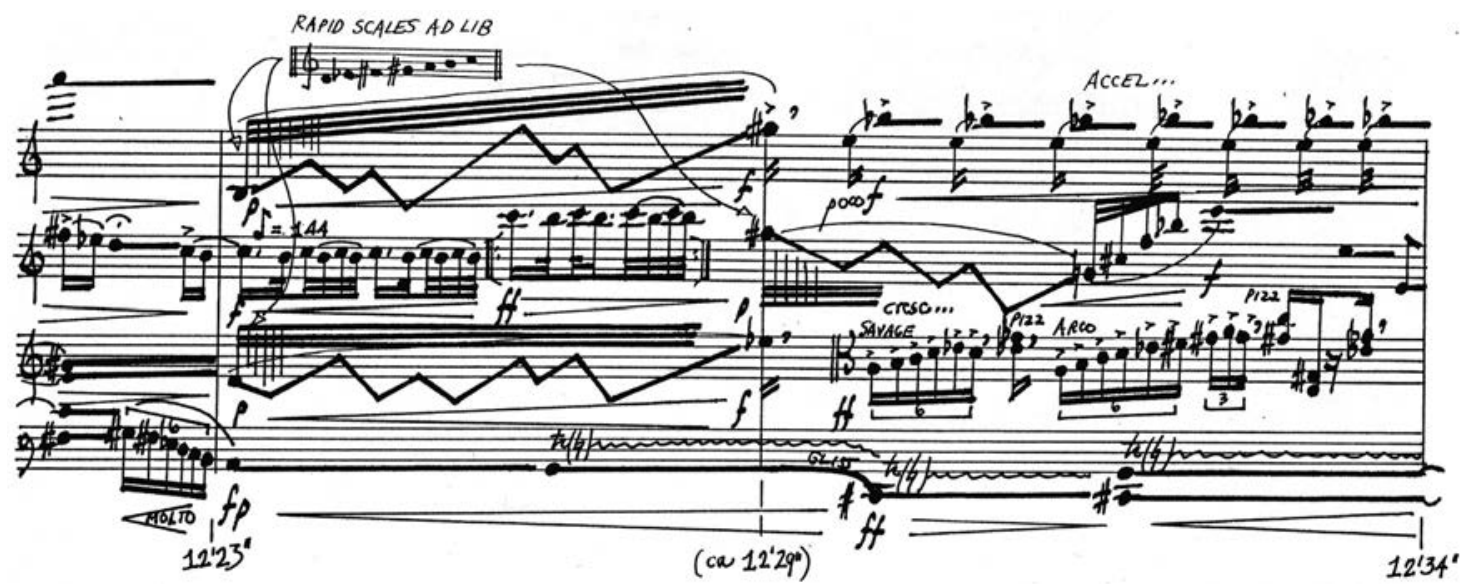

La nature marine est surprenante parfois, tel ce chant de grive solitaire que l'on retrouve soudainement au beau milieu de la mer (fig. 7).

Figure 7

Deuxième Quatuor, page 18, $2^{e}$ système

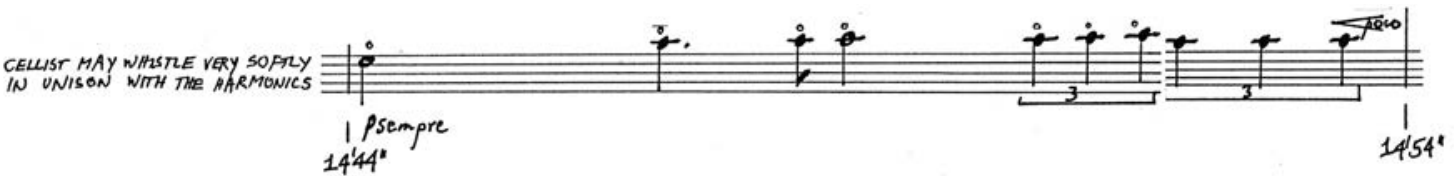

Et comme les vagues, les motifs s'enchevêtrent, se dissolvent, jaillissent et se dispersent (fig. 8). 
Figure 8

Deuxième Quatuor, page 5, $3^{\text {e }}$ système

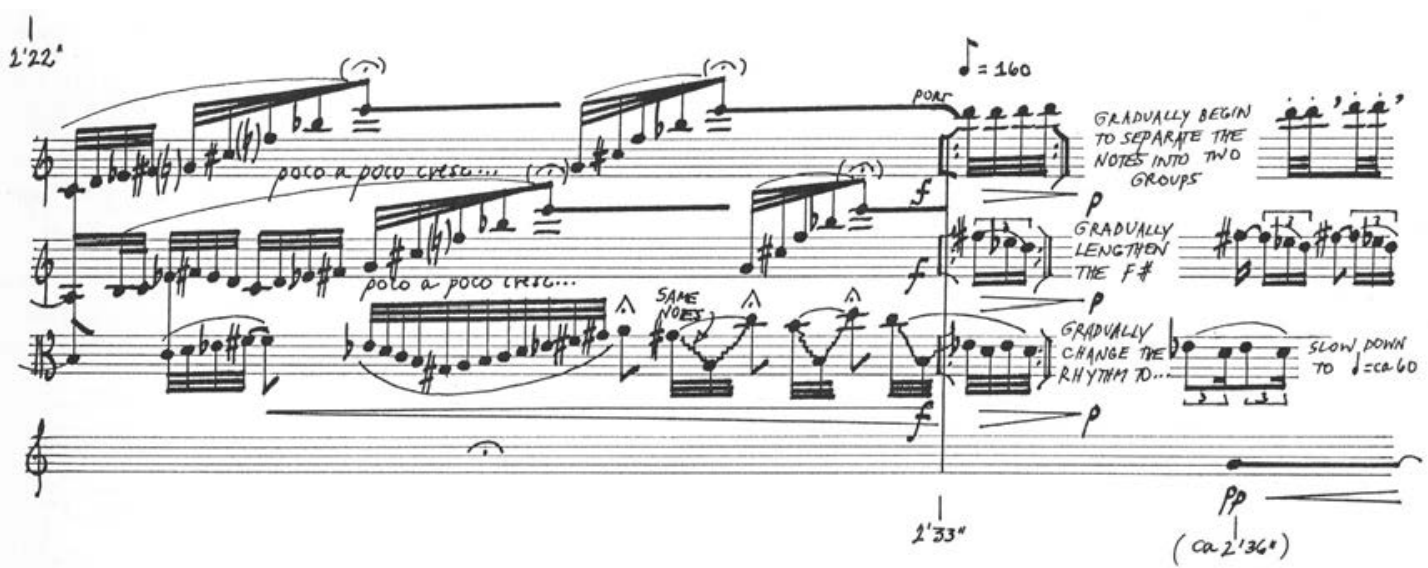

Ces nombreux motifs qui parcourent l'œuvre sont sans cesse présentés sous de nouvelles formes rythmiques, de nouvelles nuances et de nouveaux tempi. Tel un Héraclite moderne, Schafer évoque le mouvement continuel de l'eau par des ondulations dynamiques en crescendi et diminuendi et par d'incessantes variations des motifs (fig. 9).

Figure 9

Deuxième Quatuor, page 7, $4^{\mathrm{e}}$ système

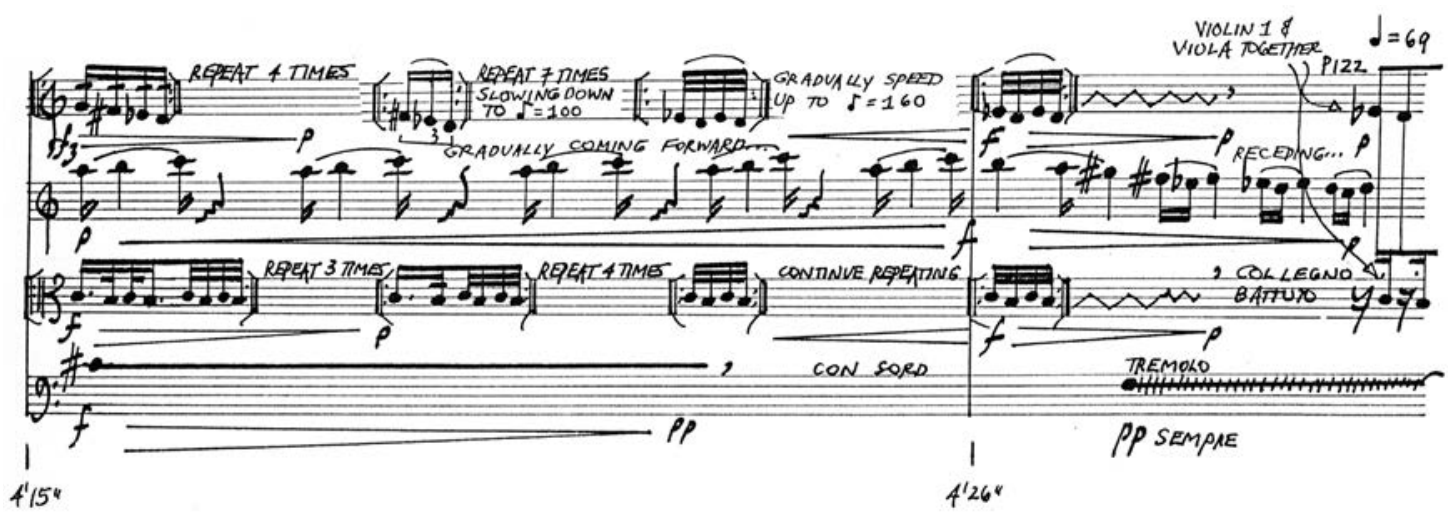

Une rare trace du monde humain se manifeste dans ce second quatuor, c'est la corne de brume d'un bateau lointain, jouée par le violoncelle et aisément reconnaissable.

C'est dans les dernières minutes du Deuxième Quatuor que débutent les jeux de spatialisations et de déplacements. La position physique des instrumentistes à 
la fin de l'œuvre sera d'ailleurs celle que l'on retrouvera au début du quatuor suivant. Ces déplacements ne seront cependant pas les garanties d'unité du cycle des quatuors, car on verra que les liens thématiques et motiviques seront encore plus prégnants.

Selon la volonté écrite du compositeur, la dernière vaguelette de l'œuvre pourrait bien être formée des murmures souriants des auditeurs, au moment où le violoncelliste cherche ses collègues au moyen d'une lunette d'approche.

\section{Troisième Quatuor (1981) ${ }^{10}$}

Nature versus culture, tel est le Troisième Quatuor.

Les antinomies y sont exposées sans compromis et sans souci dialectique, comme dans le Premier Quatuor. Car il ne s'agit pas ici d'emporter la conviction, de réfuter ou d'argumenter selon un mode musical qui chercherait à transcender les contradictions. Celles-ci seront mises en parallèle plutôt que résolves. Immanence du Janus à deux visages.

D'une certaine façon, le premier mouvement du Troisième Quatuor s'oppose au début du Premier Quatuor. Alors qu'il s'agissait de défaire des liens entre des instruments amalgamés dans le Premier Quatuor, le Troisième Quatuor pose le problème de la réunion des musiciens épars.

Île de la solitude, d'angoisses, de tensions. Le violoncelle, seul sur scène comme à la fin du quatuor précédent, entame une longue cadence dramatique soumise à l'emprise du pôle tonal la. Une grande passion s'y exprime au moyen d'une pédale sur une corde ouverte et par des frottements microtonaux qui serpentent sans cesse. Lorsque la tension entre deux notes est à son comble, la friction des ondes provoque d'inquiétants battements. Cette cadence expose aussi plusieurs des éléments que l'on retrouvera dans tout le quatuor: les quarts de ton, les sauts en tierces, les glissandi et même le chant de la grive solitaire (fig.7).

Peu à peu, les autres musiciens se surajoutent à cette trame. Tour à tour émergeant des coulisses et de l'arrière de la salle, l'alto et les deux violons font entendre des lignes musicales très contrastantes et non convergentes entre elles, comme si chacun des instrumentistes jouait pour lui-même et non avec le groupe (fig. 10).
10. Composé à Monteagle Valley, en Ontario, au cours du mois de juin 1981, le Troisième Quatuor résulte d'une commande de la Canadian Broadcasting Corporation pour le Quatuor Orford. Cet ensemble I'a créé à Boston, le 30 septembre 1981. 
Figure 10

Troisième Quatuor, page 7, $2^{\mathrm{e}}$ système

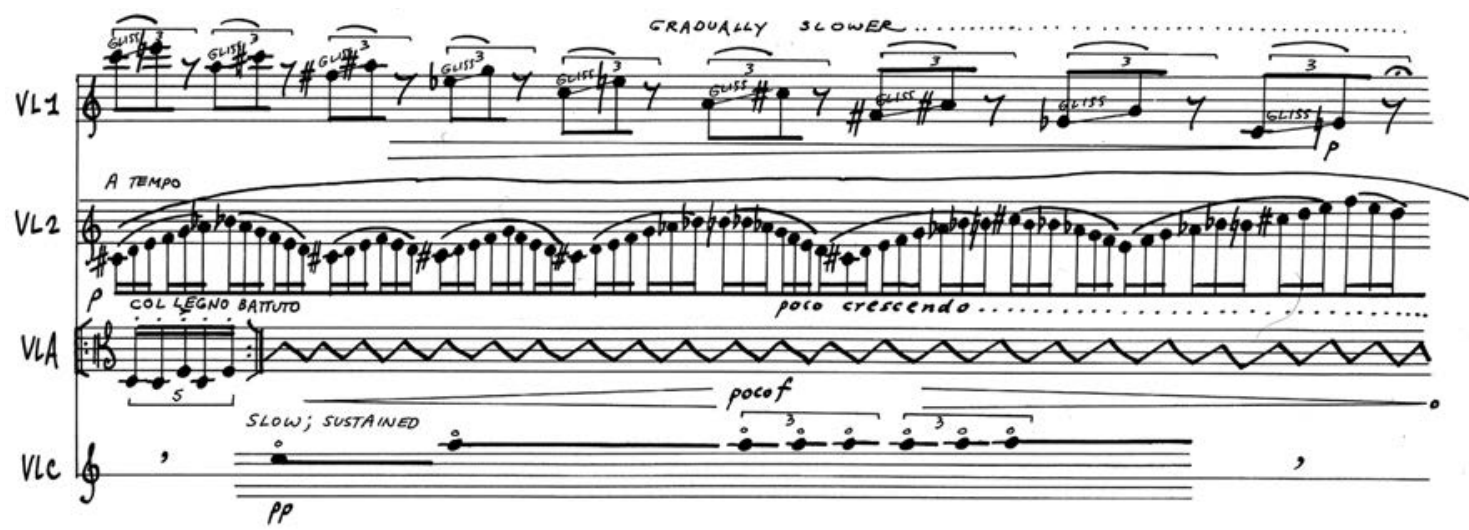

Ces superpositions n'offrent aucune occasion de résolution, jusqu'à la fin du mouvement où la solitude du second violon se pose sur l'effritement des autres voix. Le mouvement se termine lorsque les quatre instrumentistes sont enfin réunis sur scène, dans la configuration habituelle du quatuor.

Dans le second mouvement, le monde humain fait irruption avec toute sa violence. Exigeant des musiciens une force physique considérable, des cris rappelant ceux des arts martiaux viennent renforcer les notes jouées (fig. 11).

Figure 11

Troisième Quatuor, page 10, $2^{\mathrm{e}}$ système

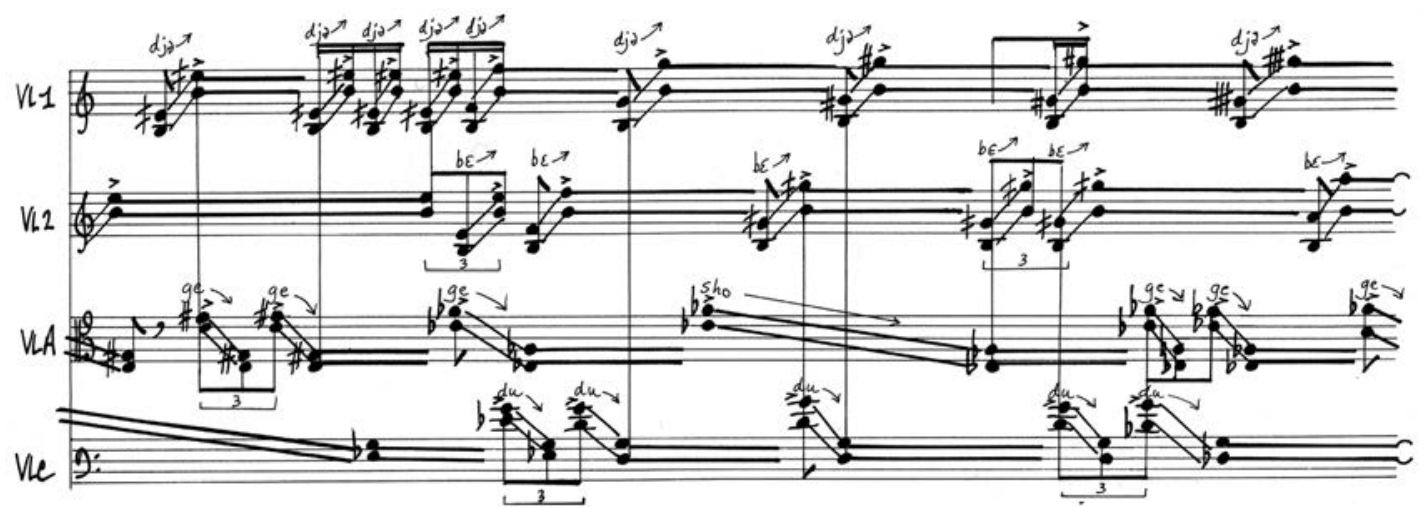

Remarquons que là comme ailleurs, la notation non conventionnelle offre à la fois la possibilité d'une plus grande complexité rythmique et d'une plus grande liberté expressive. 
Un humour d'une imaginaire comédie grinçante force à nouveau le quatuor à sortir de son cadre habituel. Les cris employés sont des gestes de déterritorialisation: om ba, ba chi, pow!, shu! et souffles de respiration (fig. 12) ${ }^{11}$.

Figure 12

Troisième Quatuor, page 11, 3e système

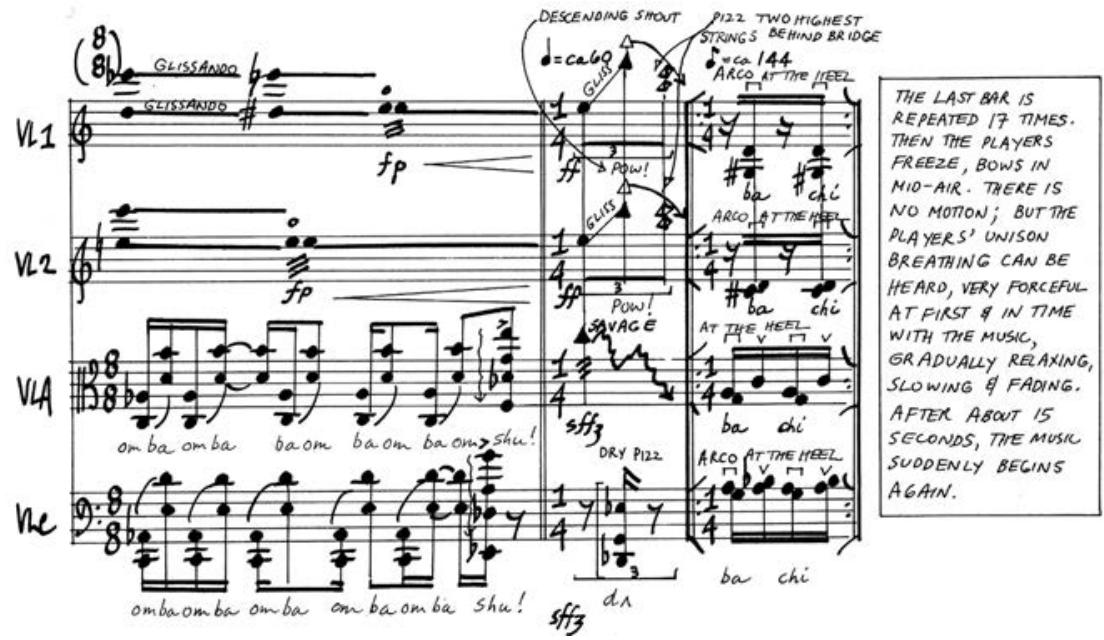

11. Le concept de déterritorialisation est emprunté aux travaux philosophiques de Deleuze et Guattari (1980).

Plus loin, comme chez Mahler, l'émergence soudaine d'un fragment de valse lente fait l'effet d'une critique acerbe du cours du monde, avec son lot de rires triviaux et le sarcasme de ses glissandi moqueurs (fig. 13).

Figure 13

Troisième Quatuor, page 14, $3^{e}$ système

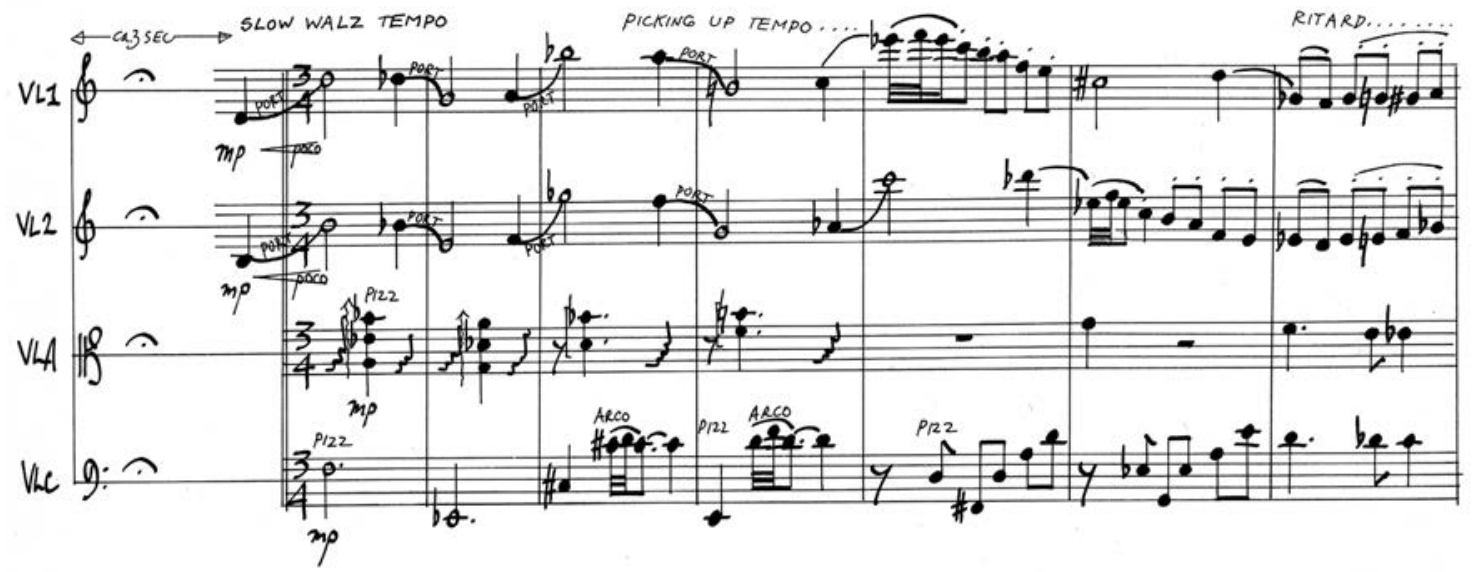


Les luttes sans merci des deux premiers mouvements font place, dans le troisième morceau, à une méditation en quarts de tons. Un unisson presque continuel se déploie sur près de huit minutes. Cette douceur soyeuse, avec ses figures troubles qui ondoient, crée une atmosphère indiscutablement ensorcelante (fig. 14).

Figure 14

Troisième Quatuor, page 21, $2^{\mathrm{e}}$ système

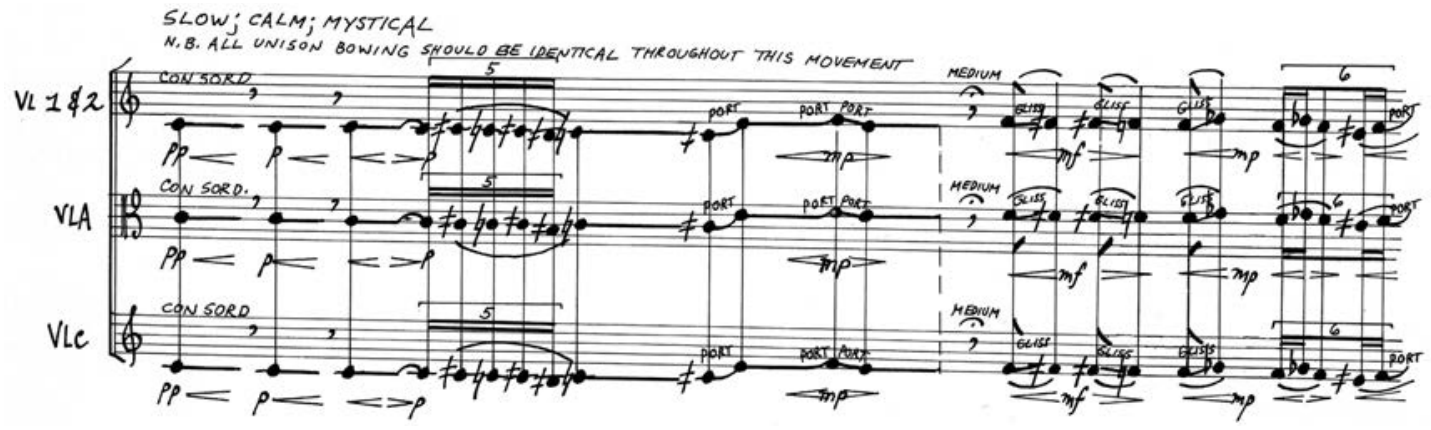

C'est un Orient rêvé, inaccessible, celui d'une sérénité intérieure imaginée ou espérée. Chaque musicien écoute les autres et les longueurs de notes sont fixées par leur respiration commune. Du rêve encore il sera question jusqu'à la fin de l'œuvre, si interrogative. Le premier violon s'éloignant vers l'arrière-scène, répète sans cesse, comme une question sans réponse, le motif ré-do-la jusqu'à l'imperceptible extinction du son. Schafer introduit là ses fameux "sons fantômes 》 basés sur l'éloignement progressif des sources sonores: entendons-nous encore réellement la séquence ré-do-la du violon maintenant situé à grande distance ou bien n'en avons-nous que l'impression, ces sons étant plutôt ravivés par notre mémoire?

\section{Quatrième Quatuor (1989) ${ }^{12}$}

L'avenir s'étend, désert et vide d'une longueur affreuse, devant lui.

Il erre seul et s'égare,

il se cherche lui-même avec fureur.

NOVALIS ${ }^{13}$

Nuit de rupture. Nuit d'adieu. Nuit de retrouvailles.

Nuit de solitude et de passages. Passage du rêve émerveillé à l'incarnation du Réel, puis de la souffrance du mortel au dialogue avec l'au-delà. Le Quatrième
12. Le Quatrième Quatuor fut composé à Indian River, en Ontario, et terminé le 5 janvier 1989. II fut commandé pour le 20 anniversaire du Quatuor Purcell, grâce au soutien du Conseil des Arts du Canada et de $M$. et $M^{m e} D^{r}$ Roland Bowman. Le Quatuor Purcell, la soprano Margarita Noye et la violoniste Joan Blackman l'ont créé à Vancouver, le 18 avril 1989. 13. Tiré de la troisième partie des Geistliche Lieder de Novalis (1943). 
Quatuor est une œuvre initiatique, une œuvre privée aussi, car le ton y est plus qu'ailleurs encore celui de la confidence et de l'épanchement, tant jubilatoire que tragique.

Si les éléments autobiographiques ne constituent en rien des garanties de réussite musicale, en revanche lorsque les sentiments sont sublimés dans la composition, la musique alors peut "exprimer quelque chose», quoi qu'en ait dit Stravinsky ${ }^{14}$. Et force est de constater que c'est bien ce qui arrive à l'écoute du Quatrième Quatuor: le ton y est personnel, intense et direct. Jamais sans doute Schafer ne sera aussi délibérément romantique que dans cette œuvre. La première page de la partition révèle le contexte autobiographique sous-jacent :

\section{In Memorium bp Nichol}

I had just begun working on the Fourth String Quartet when Paul Dutton called to tell me of Barry's sudden death. Having just seen him at a performance of The Greatest Show just a week or so before, hobbling on his crutches and obviously in great pain, but cheerful as he always was, the news that he had so quickly been taken from us affected me profoundly. I was alone on the farm at the time and as I worked, I kept thinking of the many times we had been together and the projects we had worked on.

Curiously I had begun playing with a theme from The Princess of the Stars, thinking to incorporate it in the new work when I suddenly realized that it was part of the chant Barry had delivered in his performance of that piece at Banff three years ago. Aside from this, there is probably little in the work to remind anyone of Canada's greatest poets, but the work is dedicated to his memory with the hope that, wherever he is, it may give him some pleasure.

Another influence, also personal, affected the work. My wife Jean returned to me, dispelling the loneliness and reinforcing my faith in the living moments, so few before we all must depart into the long night.

Ce programme intime est donc, comme pour les autres quatuors, marqué par une irréconciliable dualité : joie et peine, rupture et retrouvailles, vie et mort. La musique va d'ailleurs juxtaposer, en quatre épisodes, ces oppositions. Cette faculté de dédoublement romantique permettra, de la même manière que chez E. T. A. Hoffmann, à qui le compositeur s'est beaucoup intéressé par ailleurs ${ }^{15}$, d'échapper au Réel. Comme souvent nous semble-til dans la musique de Schafer, il ne s'agit pas de transcender les conflits avec une visée synthétique, mais plutôt de passer à travers eux en assumant cette lutte des contraires d'une manière profondément héraclitéenne. Ainsi, le temps lisse, d'une lyrique triste au début et à la fin de l'œuvre, s'oppose complètement et sans réconciliation possible au temps strié des rythmes vivaces de la partie centrale. Doubles, encore.

Premier épisode. Le début est lyrisme et mystère. Sur des accords presque glauques, sans vibrato, se détache du lointain le chant du premier violon en détresse
14. "Je considère la musique comme impuissante à exprimer quoi que ce soit » (Stravinsky, 1962).
15. Ernst Theodor Amadeus Hoffmann (1776-1822). (Voir Schafer, 1975.) 
(fig. 15). II est à l'arrière-scène et déroule une sinueuse et longue mélodie fondée sur la cellule fa dièse - mi bémol - ré, qui irriguait le Deuxième Quatuor (voir aussi supra: fig. 6).

Figure 15

Quatrième Quatuor, page 2, $1^{\text {er }}$ et $2^{\mathrm{e}}$ systèmes

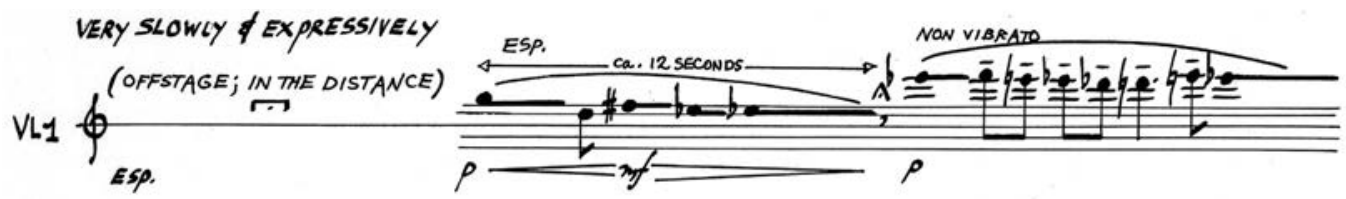

VL1

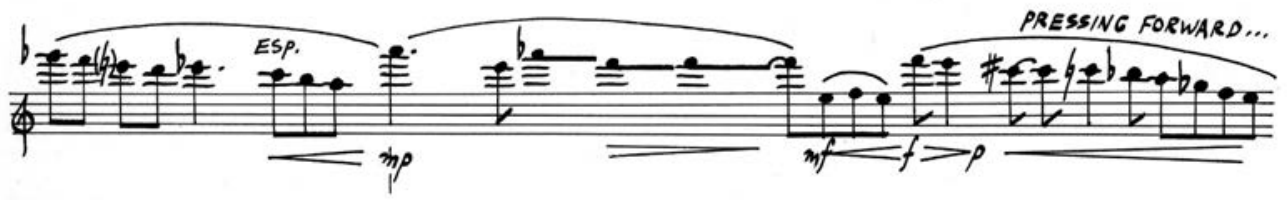

À mesure que le violon se rapproche pour rejoindre les autres musiciens sur scène, le caractère se fait plus incarné, plus réel (fig. 16).

Figure 16

Quatrième Quatuor, page 6, $1^{\text {er }}$ système

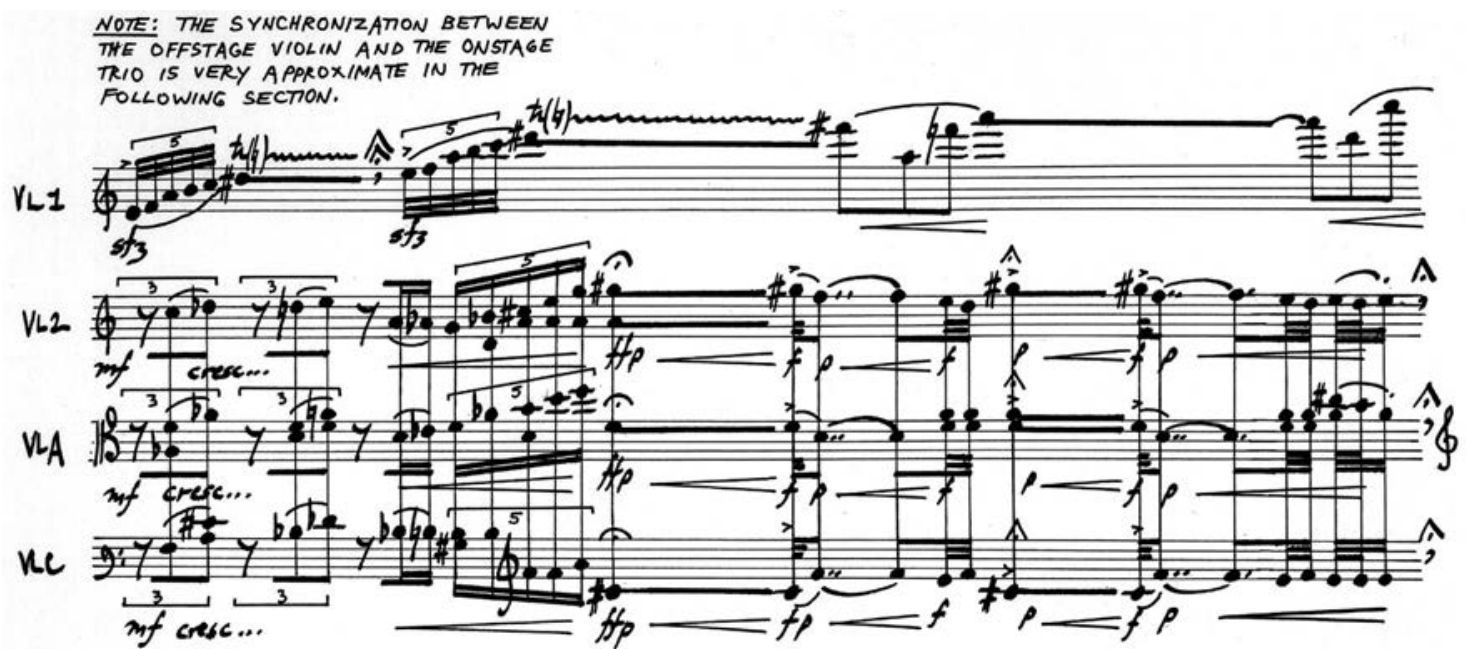

Ce passage de l'absence au retour exprime, d'une tout autre manière, la même idée que celle qui préside à la sonate dite Les Adieux de Beethoven. Et vient le second épisode de joie extatique, de joie sans mélange (fig. 17). 
Figure 17

Quatrième Quatuor, page 9, $3^{e}$ système

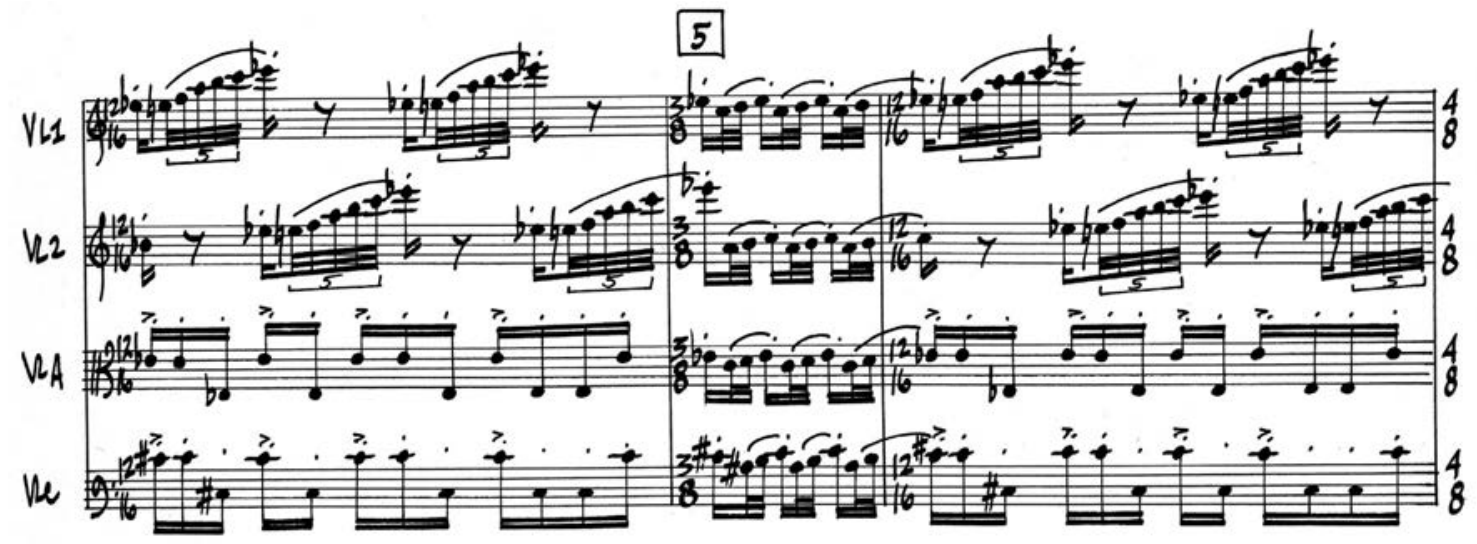

Schafer fait appel ici à une écriture ludique et convulsive, pleine de brillantes envolées, d'ostinati, de glissandi et de grandes cascades de pizzicati. Une force majeure y déferle, celle de l'homme retrouvant l'épouse qui l'avait quitté ${ }^{16}$, typique du sourire épanoui de l'Aurige de Delphes ${ }^{17}$. Sur 126 mesures se déploie une rage de vivre motorique et qui n'est pas sans évoquer Chostakovitch par endroits (fig. 18).

Figure 18

Quatrième Quatuor, page 15, $1^{\text {er }}$ système

16. Voir la notice de la première page de la partition citée ci-dessus.

17. L'Aurige de Delphes est une des plus belles statues grecques de la fin de l'époque archaïque (478 av. J.-C.) (Rosset, 1983).

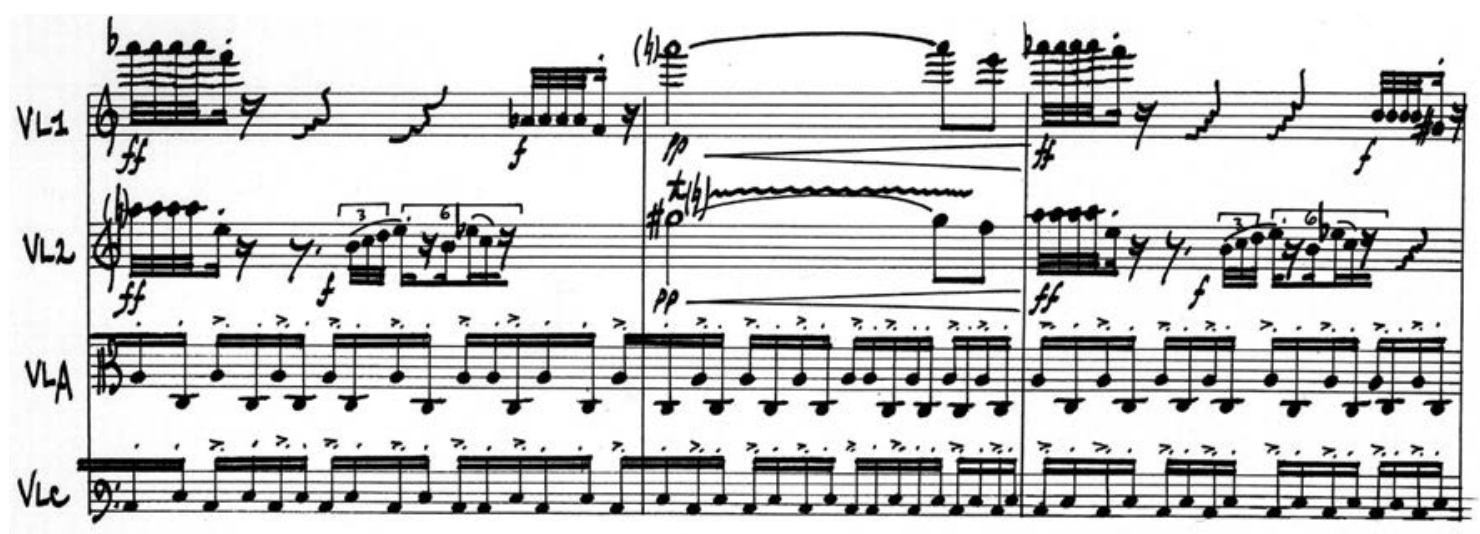

Au sommet de l'excitation jubilatoire de cette nouvelle noce, survient, sans préparation aucune, le troisième épisode. À la onzième minute, c'est la cassure, la mort. Clusters impitoyables (fig. 19). 
Figure 19

Quatrième Quatuor, page 23, $1^{\text {er }}$ système

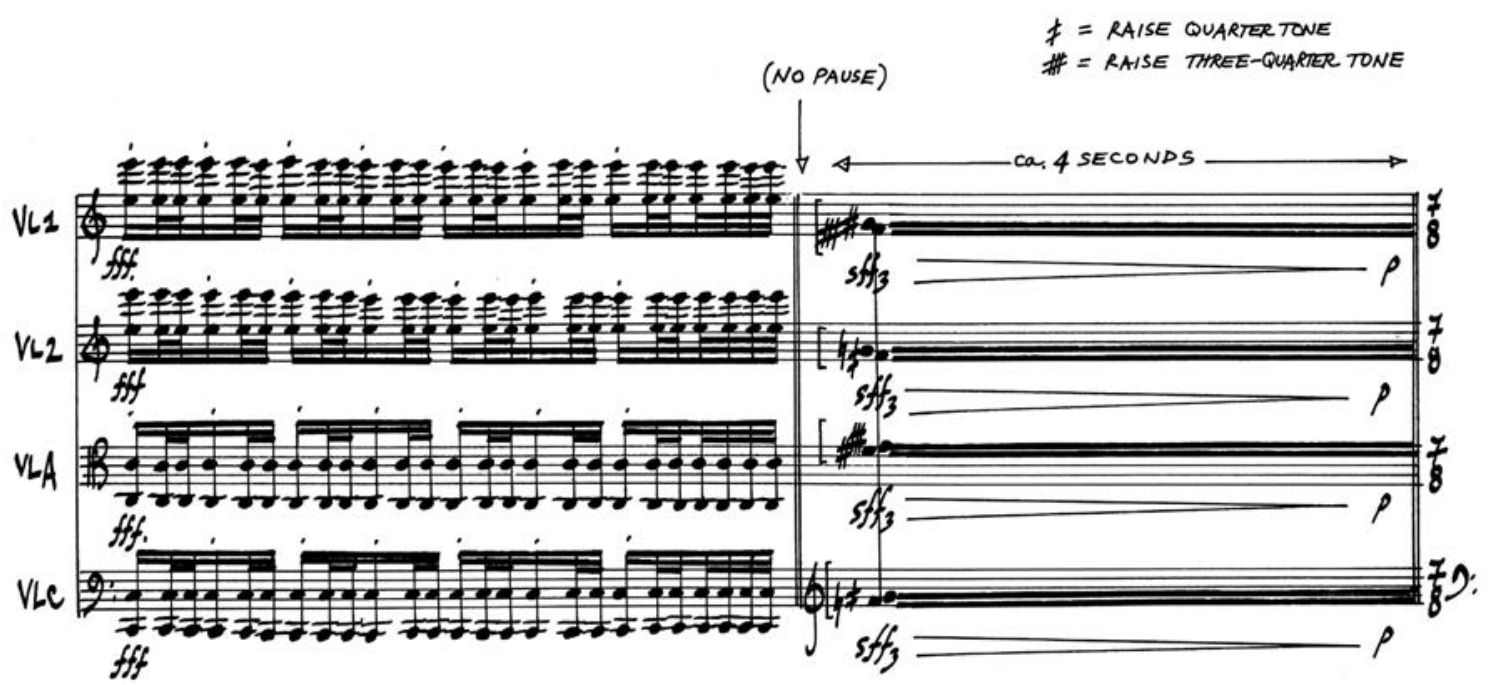

L'expérience de la mort de bp Nichol et de la solitude du compositeur face à cette séparation, toute privée qu'elle soit, est palpable dans la musique. Sur fond de glissandi profondément douloureux, émerge la voix seule de l'alto, désespérée (fig. 20).

Figure 20

Quatrième Quatuor, page 24, $2^{e}$ et $3^{e}$ systèmes

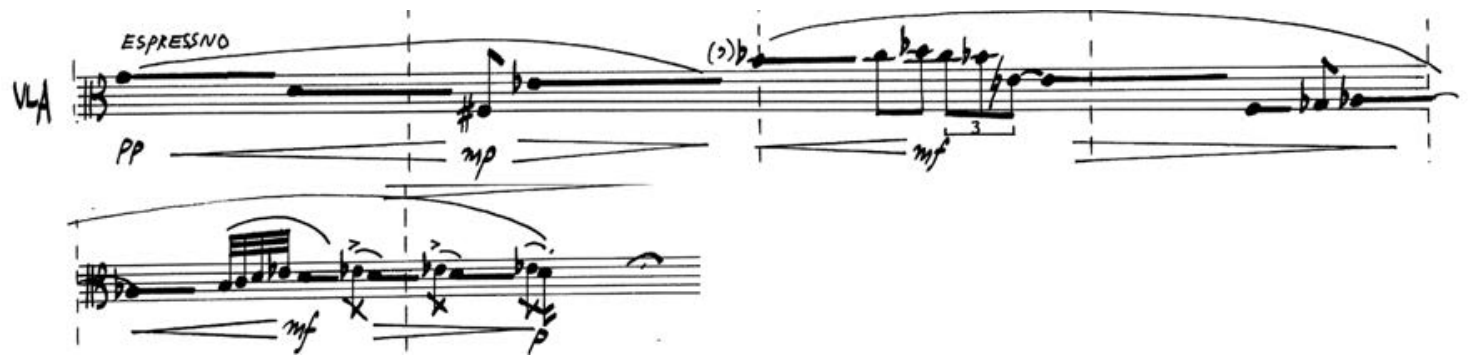

Jusqu'aux soubresauts d'exubérance qui précèdent la fin: presque aucune lumière. Puis viennent ces éclairs sur l'au-delà du bref quatrième épisode, dans une magie sonore typique de Schafer, comme si nous étions en contact avec l'Ailleurs (fig. 21). Depuis l'arrière-scène, un autre violon et une voix se font entendre au loin sur un fond $d^{\prime}$ harmoniques du quatuor ${ }^{18}$.

18. Thème romantique, là encore, comme lorsque Mahler confie à la flûte un chant d'oiseau supranaturel vers la fin de sa Seconde Symphonie, juste avant l'entrée du chœur (Mahler, 1975, p. 185, 5e mouvement, mesures 448 à 471 ). 
Figure 21

Quatrième Quatuor, page 29, $1^{\text {er }}$ système

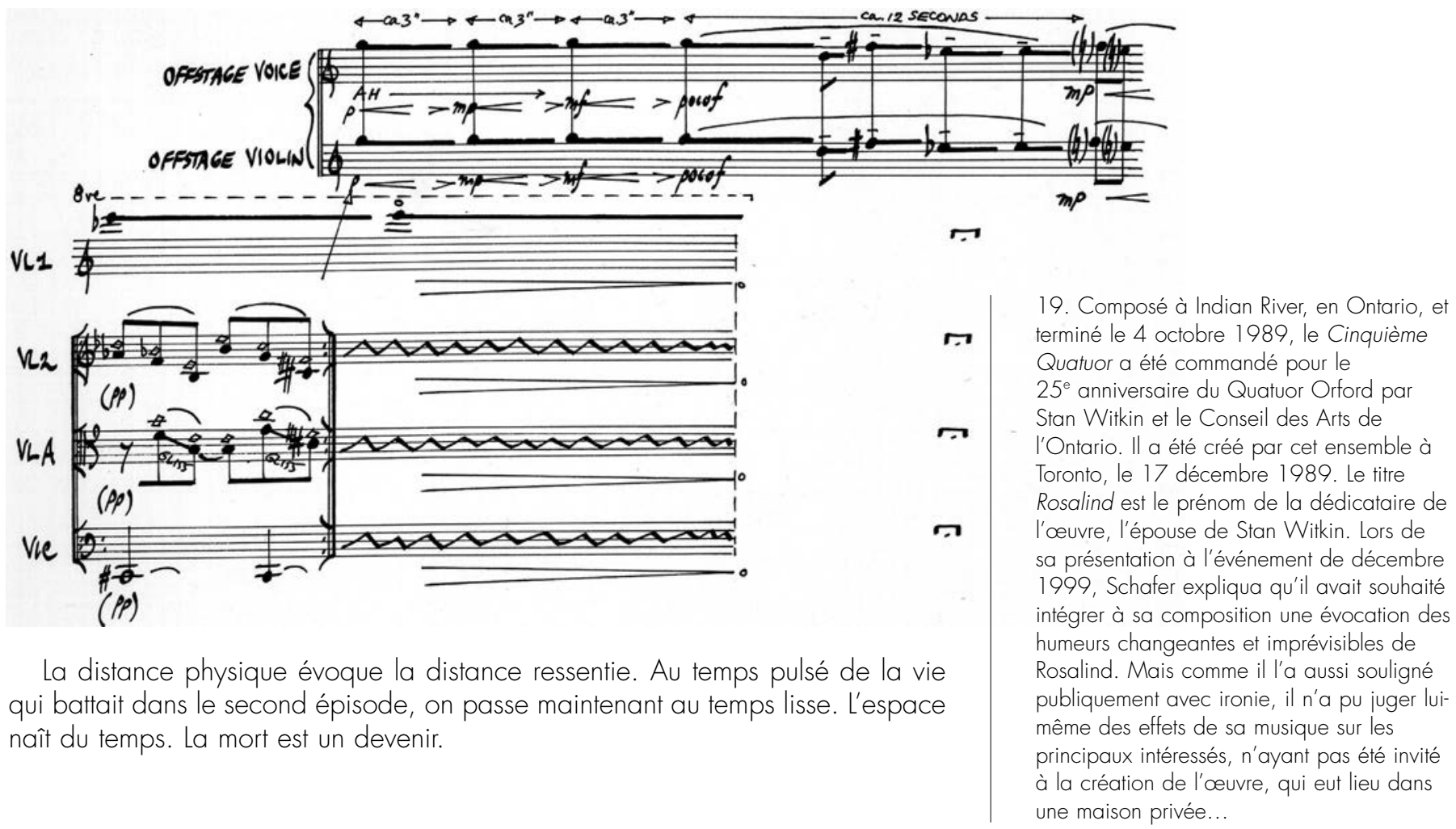

\section{Cinquième Quatuor : Rosalind (1989) ${ }^{19}$}

On ne peut pas entrer deux fois dans le même fleuve.

HÉRACLITE (fragment 91)

Transitions infimes, transformations imperceptibles. Jeux amoureux. Variations infinitésimales. La nuit, de subtiles différences comme de fines ressemblances peuvent se percevoir.

Une fraîcheur élégiaque ouvre le Cinquième Quatuor dans un contraste de ton avec la fin du précédent quatuor, dont le Cinquième reprend pourtant l'exacte phrase finale (fig. 22). 
Figure 22

Cinquième Quatuor, page 2, $1^{\text {er }}$ système

\section{Fifth String Quartet}

(ROSALIND)

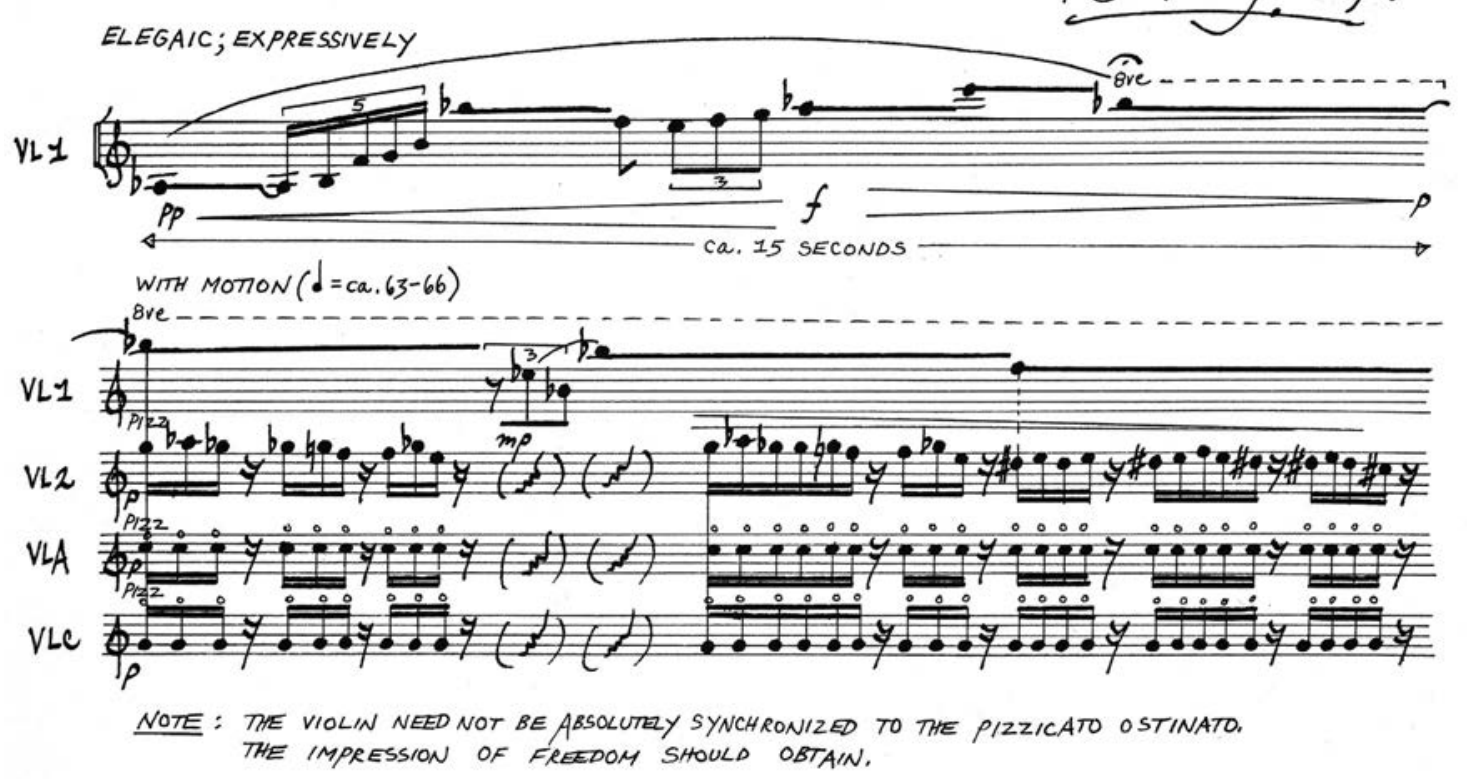

Cette première phrase, confiée à un instrument solo comme ce sera également le cas dans les Sixième et Septième Quatuors, commence l'œuvre dans un geste simple mais très efficacement narratif. Cette fonction est selon nous de même nature que celle de l'idée fixe berliozienne qui inaugure la Symphonie fantastique. Dessous, un ostinato rythmique de pizzicati qui va hanter toute l'œuvre. On retrouve également le motif d'Ariane, esquissé par le violon dès le début (mi bémol - si bémol - si bémol - fa).

Retour de la nature aussi, absente peut-être davantage des Troisième et Quatrième Quatuors, et qui reprend ici ses droits. Le hurlement du loup, transcrit habilement par Schafer au violoncelle, va lui aussi venir habiter l'espace. 
Figure 23

Cinquième Quatuor, page 3, $3^{\text {e }}$ système

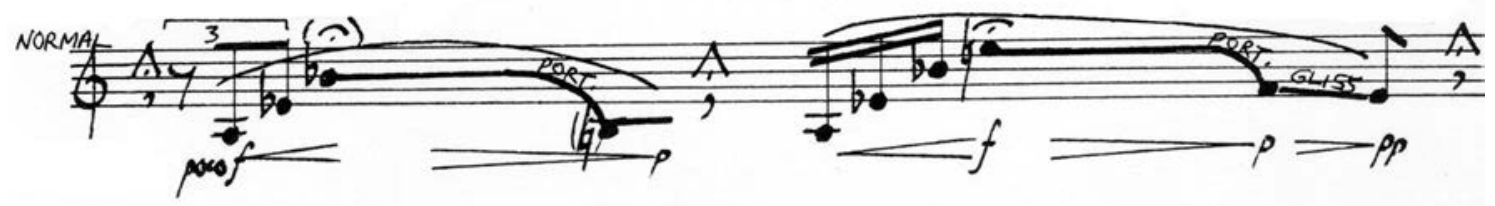

Ces matériaux posés, le travail compositionnel consistera à agencer les transitions, à fondre les passages d'un état à un autre avec le plus de naturel possible. Dans ses échanges avec le public lors de l'événement montréalais de décembre 1999, le compositeur s'est expliqué sur ses intentions :

Ma préoccupation majeure était d'écrire une pièce représentative de ce que j'appellerais le temps existentiel. Qu'est-ce que cela veut dire? Je parle du temps tel que nous le percevons entre une tasse de café et un mal de dents. Partout dans nos vies, le temps est structuré pour nous. La musique est une de ces structures; le rythme, la durée, le temps, la forme, le mouvement, tous ces éléments projettent une sorte de facticité par rapport à nos changements d'humeur. Je voulais créer une pièce où la modulation d'un état à un autre ne permettrait pas à l'auditeur de cerner le moment précis du changement. Pour un jeune compositeur, il est très difficile d'établir des liens entre deux idées différentes. Les idées viennent facilement, la façon de les intégrer requiert toutefois plus de travail. Pour moi, un grand compositeur se distingue par sa façon de pouvoir créer des modulations indétectables d'un état à un autre; et il est d'autant plus étrange de constater que ce processus est extrêmement difficile quand on réalise que c'est le déroulement naturel de la vie.

Ces préoccupations formelles ne sont pas rares chez Schafer ${ }^{20}$, simplement, elles sont toujours subordonnées au résultat musical et aux nécessités expressive, poétique et narrative. Nous ouvrons ici une longue parenthèse à notre parcours pour aborder cette question de forme et son corollaire, le style, dans les quatuors de Schafer.

Schafer n'est pas un "compositeur à problèmes", en ce sens que son objectif n'est pas de créer de nouvelles structures musicales aptes à résoudre des problèmes de composition à la manière des jeux de blocs de nombreuses musiques intellectuelles de la fin du $x x^{e}$ siècle. Au contraire, sa musique place les questions de forme au même rang que le propos musical, sans que les structures ne viennent opacifier le discours. C'est sans doute là un des nombreux points qui le distancie de plusieurs de ses contemporains, davantage intéressés à des questions de pure structure. C'est aussi là que se reconnaissent le mieux les choix esthétiques de la musique de Schafer pour quatuor à cordes : même lorsque des préoccupations formelles sont mises de l'avant (comme dans ce Cinquième Quatuor et comme ce sera aussi le cas du Sixième Quatuor) la musique s'écarte tout de même sensible-

20. Ainsi, la «forme » du Deuxième Quatuor est celle du rythme des vagues, celle du Sixième Quatuor, des mouvements de Taï Chi, celle du Septième Quatuor est donnée par le poème enchevêtré de la diva schizophrène, etc. 
ment de la longue lignée des musiques pour quatuor à cordes, conçues comme des structures savantes et âpres dont la Grosse Fuge opus 133 de Beethoven constitue le parangon ${ }^{21}$ et dont les prolongements récents sont nombreux et variés, par exemple, Archipel II de Boucourechliev, le Livre pour quatuor de Boulez, le Troisième Quatuor de Carter, le Premier Quatuor de Ferneyhough et plusieurs autres. Le dénominateur commun de ce groupe d'œuvres serait, à notre avis, d'associer polyphonie complexe et sévérité du discours, jeux structurels et sonorités revêches; comme si le sérieux et l'importance des jeux de forme ne pouvaient qu'être mieux défendus et portés que par une attitude musicale stoïque qui ne fasse aucun compromis à la beauté sonore. On répliquera que l'âpreté est aussi une forme de beauté, bien sûr. Mais il s'agit là d'une beauté qui se fait un point d'honneur de refuser la séduction sonore. Or, la musique du Cinquième Quatuor, comme celle de plusieurs autres quatuors de Schafer, s'écarte de cette lignée, principalement parce qu'elle recourt à cette séduction sonore, à l'emploi de repères de tonalité aussi bien qu'à des timbres et à des rythmes accrocheurs ${ }^{22}$. Nous soutenons ici que même en s'écartant de la lignée concentrée et sévère des questions de forme et de structure selon l'approche invoquée, Schafer répond à sa manière (surtout dans les Cinquième et Sixième Quatuors) aux questions de forme et de structure compositionnelle du quatuor à cordes aujourd'hui. Simplement, il intègre de manière continuellement souple ces questions de forme à l'expressivité et à la narrativité de son style. En revanche, à l'audition, on peut aisément ignorer les transformations cachées de la partition et n'écouter que le défilement des voix dans leur jeu plus ou moins évident de transformations réciproques.

Un certain débat, qui déborde largement le Cinquième Quatuor, nous semblet-il, mais qui se pose avec une acuité particulière dans ce cas, doit être évoqué. \|l s'agit de la question du style d'écriture de Schafer, jugé par une partie de l'avant-garde comme traditionnel en raison, entre autres choses, de son recours à la tonalité, de son caractère romantique aussi; ou considéré par certains comme suspect par son caractère enjôleur et par son refus de s'inscrire dans la lignée de la musique dite "savante". C'est que depuis Darmstadt, comme plusieurs l'ont constaté, l'emploi d'un pôle tonal comme d'une expression passionnée en musique sont perçus comme des retours en arrière, comme des reculs historiques. La conception hégélienne qui veut que la musique, comme l'histoire, "avance" inexorablement dans son évolution paraît pourtant éculée, risible même, à bien des compositeurs actuels qui travaillent en dehors d'une préoccupation d'inscription dans la chaîne historique.

En dernière analyse, c'est selon nous la seule réussite de l'expression musicale qui devrait compter, bien davantage que la question de la rectitude stylistique. Nul mieux que Mikel Dufrenne n'a approfondi la question des rapports entre le style et l'expression dans le cas de la création d'œuvres d'art.

Il faut enfin se demander comment le passage de la singularité à la valeur - à l'absolu de la valeur - peut être franchi. Lorsque l'expression de l'être-soi n'est ni indis-
21. Cela a par exemple conduit le Quatuor Arditti à ne jouer que cette œuvre de la tradition historique précédant Schönberg. Ce choix est significatif et instructif, car il montre bien le pouvoir symbolique associé aux jeux structurels dans la conception historique de l'évolution du quatuor à cordes (voir la table ronde à ce sujet dans le présent numéro). II faudrait pourtant nuancer longuement cette forme de réduction de la musique de Beethoven à sa partie la plus complexe (c'est une fugue après tout), car le corpus du maître de Bonn contient aussi de nombreuses pages romantiques avant I'heure lop. $59 \mathrm{n}^{\circ} 1$, op. 131, op. 132 pour $n$ 'en citer que trois) et qui ne vont pas du tout dans cette direction.

22. À ce titre, il est intéressant de rappeler que la même opposition entre le style plus lyrique de Berg et celui plus concentré de Webern fut un des débats importants de l'après-guerre, soulevé notamment par Boulez. 
crète ni arbitraire, lorsque la singularité est assez authentique pour se hausser à l'universel. Non point l'universel de la rationalité qui se révèle à ce que tous peuvent suivre un raisonnement, mais l'universel de la sensibilité qui fait que tous peuvent accéder à un monde. L'universel ne va pas sans la nécessité. Cette nécessité dans le sensible - dans la chair et le sens de l'objet - mesure la qualité de l'œuvre, et non d'une subjectivité. Elle requiert à la fois l'invention et la maitrise des moyens, mais aussi que s'exprime dans l'œuvre, par ces moyens, un visage singulier de la Nature vécu par le sujet créateur. Ce sujet est là pour le vivre: pour répondre à un appel lancé par la Nature. L'universel a sa caution dans la Nature. Et, si le style est la marque de l'ouvrier sur son ouvrage, c'est dans la mesure où l'ouvrier laisse cette marque être celle de la Nature qui l'inspire. (Dufrenne, 1995, p. 698)

Si le pari de la nécessité sensible est réussi - comme nous le pensons - la musique réalise d'elle-même le projet esthétique et le débat sur la rectitude du style peut être mis à l'écart. Quoi qu'il en soit, la question formelle des structures et des transitions infimes dans l'œuvre de Schafer mériterait le développement d'une longue analyse dans le cas du Cinquième Quatuor. Refermons donc notre parenthèse et examinons quelques exemples de ces transitions. Voici un premier exemple, tiré de l'introduction, avant la section notée A (fig. 24, p. 36).

S'y fondent en quelques instants les motifs en pizzicati du début et la cantilène du violon inspirée du motif d'Ariane pour préparer l'apparition du motif du loup au violoncelle, sur fond des lents sons glissés du trio (fig. 24, p. 36).

Et puis il y a ces atmosphères nocturnes, ces bruits et murmures de la nature, ces fureurs sauvages (fig. 25, p. 37).

Jamais insistantes pourtant, ces fusées brutales qui disparaissent aussi soudainement et imperceptiblement que possible. Doubles? Plutôt des multiplicités. Les visages s'ajoutent les uns aux autres et le Cinquième Quatuor déroule ses changements de caractères pourtant si contrastants dans une continuelle fluidité temporelle, avec une aisance confondante. Cette maîtrise de l'écriture - le compositeur connaît à fond toutes les subtilités du jeu des instruments à cordes - satisfait les interprètes qui y trouvent, malgré la difficulté d'exécution, un naturel appréciable. Et les changements se succèdent, à la manière des changements d'humeur de Florestan / Eusebius, rapides et évanescents (fig. 26, p. 37).

Ici, un écho lointain mais subtil de la Suite lyrique de Berg passe, comme une bribe de dialogue entre le présent et le passé (fig. 26, p. 37).

Et de nouveau, comme dans les vagues du Deuxième Quatuor, les textures sont impressionnistes et celles-ci évoquent maintenant les charmes d'une nuit d'amour aux accents espagnols, voire quasiment mélodramatiques (fig. 27, p. 38). 
Figure 24

Cinquième Quatuor, page 3, $1^{\text {er }} 3^{\text {e }}$ systèmes
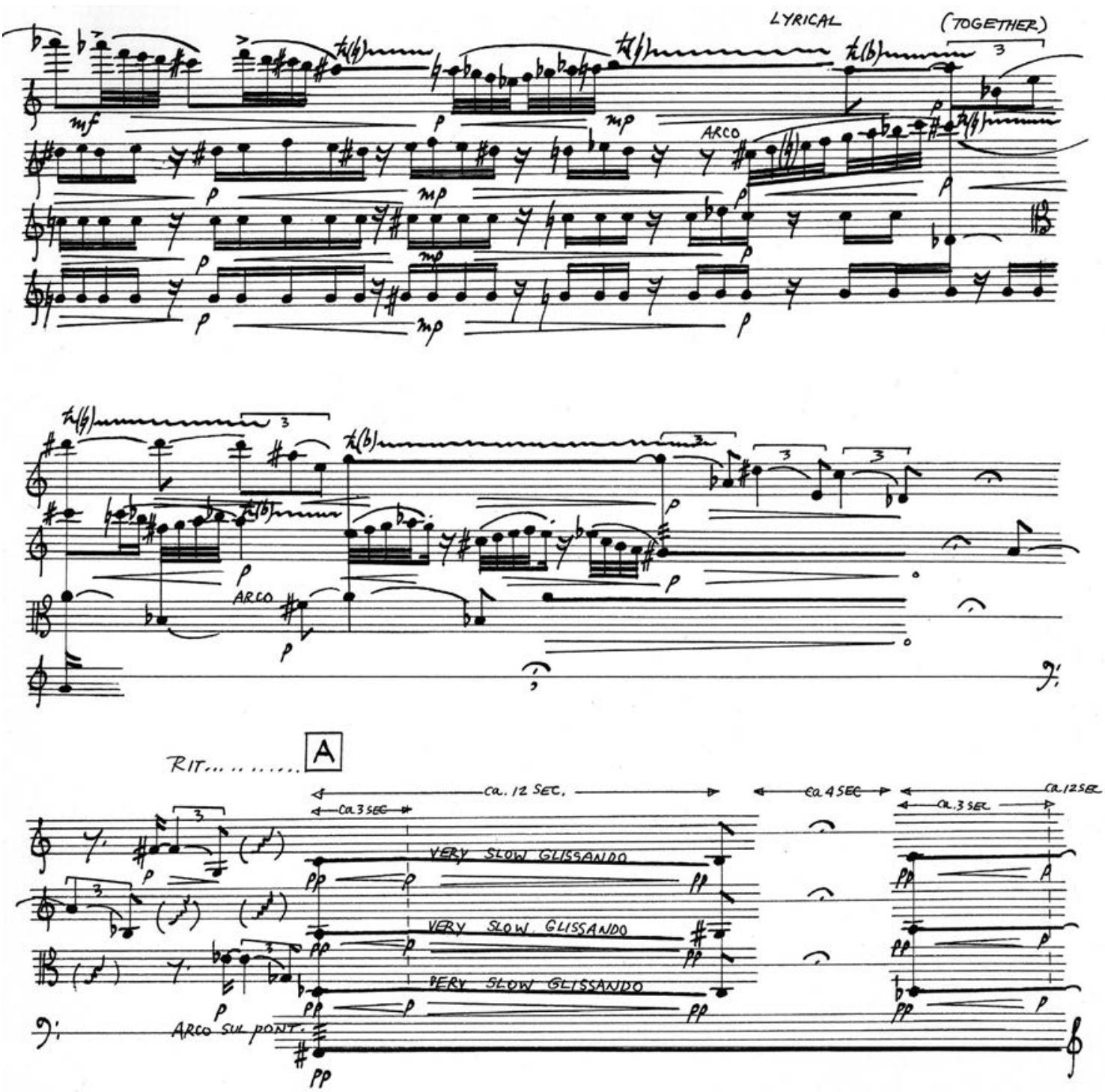
Figure 25

Cinquième Quatuor, page 5, $3^{e}$ système

SAVAGE; BRUTAL (SAME TEMPO AS PREVIOUSLY)

ROUGH, HARSH PI22

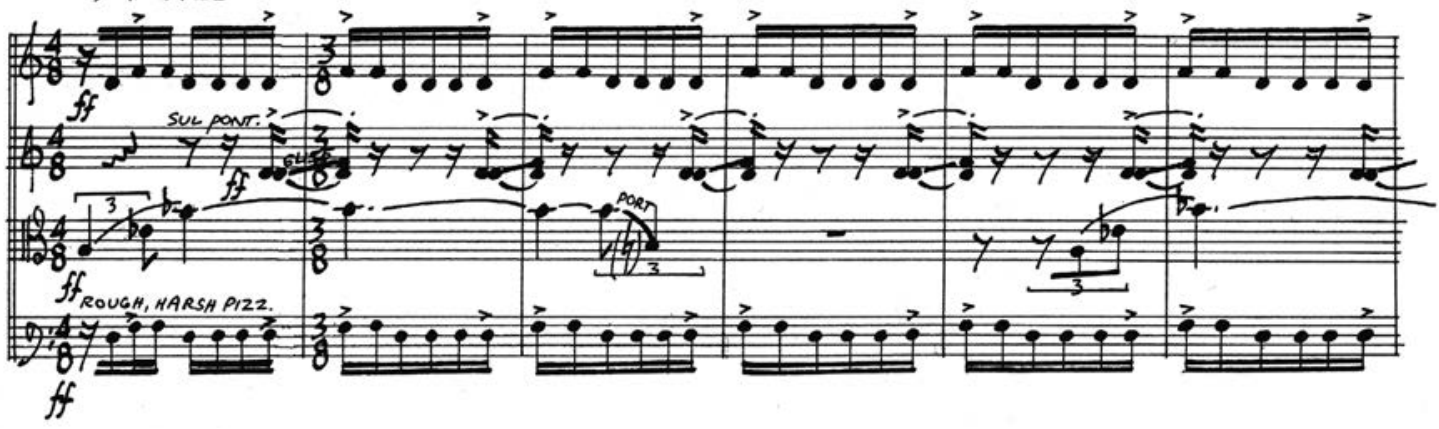

Figure 26

Cinquième Quatuor, page $13,1^{\text {er }}$ et $2^{\mathrm{e}}$ systèmes

INDEPEUDENTZY OVERLAPPING

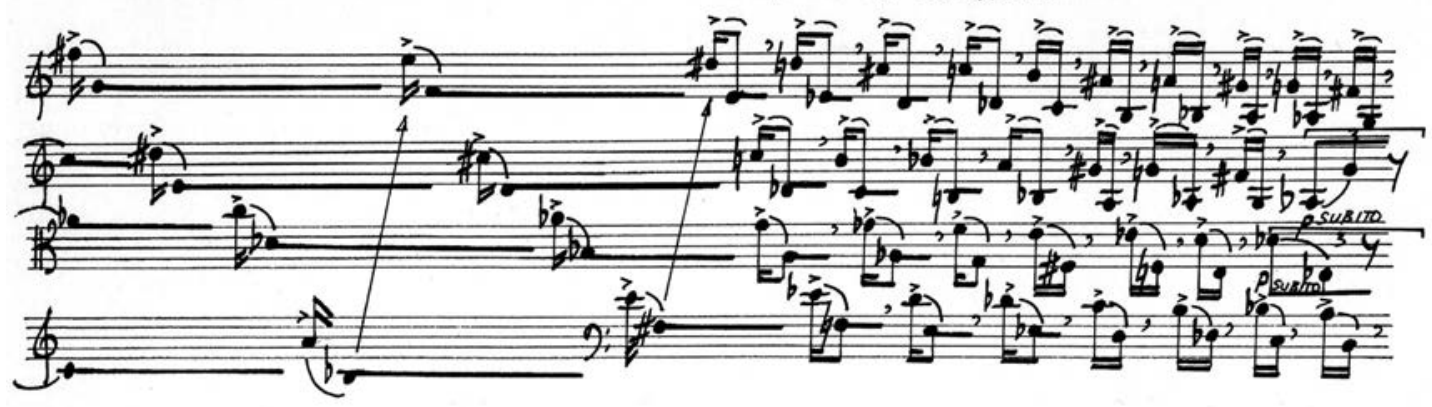

INDEPENDENT RITARD...

MOLTO RIT...

J $\angle Y R I C A \angle$

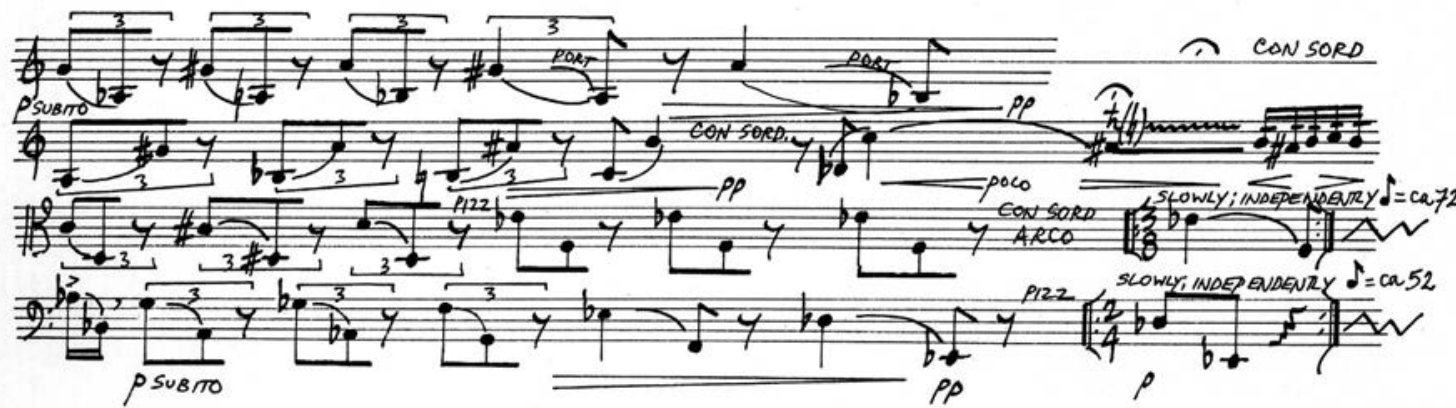


Figure 27

Cinquième Quatuor, page 14, 3e système

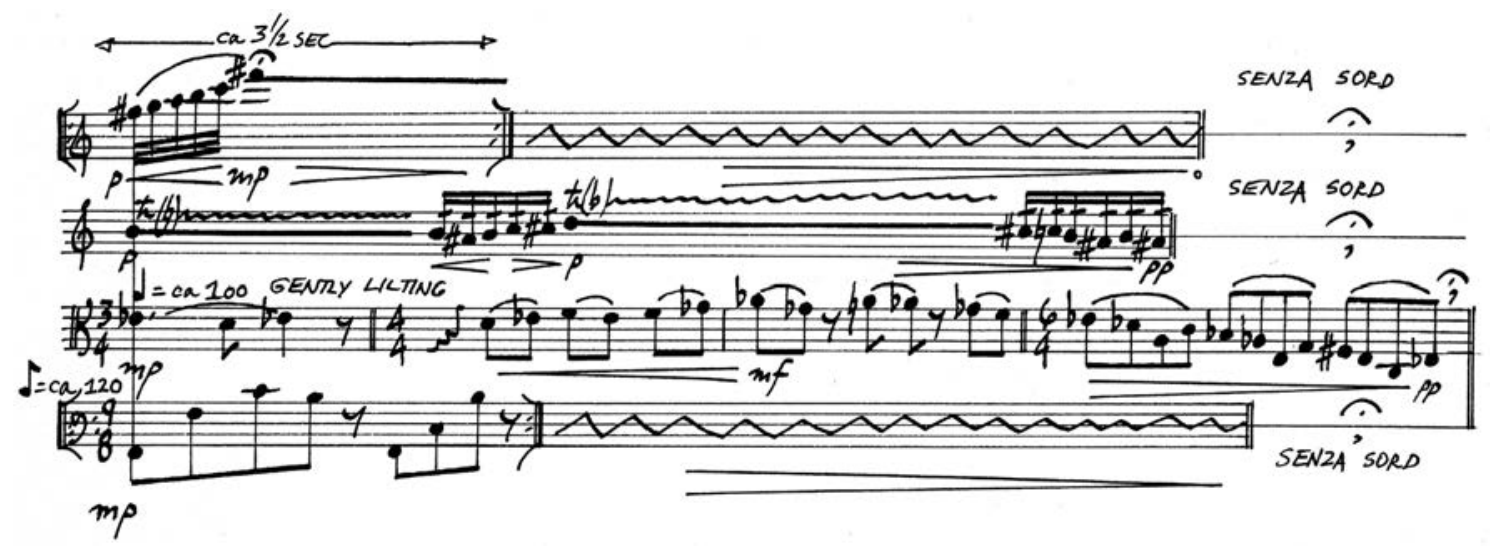

Des couleurs ravéliennes tout à coup, puis très vite autre chose. Retour aux inquiétudes et reprise variée des furies rythmiques. Eł que de changements de caractère et de variations imbriquées ${ }^{23}$ ! Chaque page de la partition regorge de ces transformations à la fois fines et contrastées, un peu comme au final du second acte des Nozze di Figaro de Mozart.

Jusqu'à la fin, il y aura absence complète de toute tentative de convaincre par les ruses de la dialectique démonstrative. Seulement des enchaînements raffinés du compositeur-joueur qui semble s'amuser plus que jamais de la malléabilité qu'il imprime à son matériau de base.

La fin, véritable petit nocturne aussi touchant qu'empreint de simplicité rêveuse, use du chatoiement des crotales en appoint des envoûtantes sonorités harmoniques des cordes et des rappels rythmiques en pizzicatti qui ouvraient le quatuor. Nuit de rêve, enfin!
23. Selon la manière de dénombrer les épisodes que l'on adopte, on peut compter entre 26 et 30 sections distinctes dans le Cinquième Quatuor.

24. Le Sixième Quatuor a été composé à Indian River, en Ontario, et terminé le 3 mars 1993, puis copié et révisé le 13 avril 1993. II résulte d'une commande de Micheal Koerner, du Conseil des Arts du Canada et de la Canadian Broadcasting Corporation pour le Scotia Festival. Le Quatuor Gould en a assuré la création au cours du Scotia Festival, en juin 1993. Intitulé Parting Wild Horse's Mane, ce Sixième Quatuor fait ainsi référence au mouvement de Taï Chi du même nom. La partition est divisée en 108 sections qui correspondent minutieusement à la séquence des mouvements de Taï Chi.

\section{Sixième Quatuor (1993) ${ }^{24}$}

un devenir n'a pas de sujet distinct de lui-même

DELEUZE ET GUATTARI 25

Devenir-nuit. Devenir-imperceptible. Devenir-animal.

La diversité des strates du Sixième Quatuor est étonnante: tout y va dans le sens d'une musique secrète, d'une musique sorcière ${ }^{26}$, d'un devenir-secret, d'un devenir-nuit, d'un devenir-ritournelle.
25. La présente section sur le Sixième Quatuor utilise quelques concepts de ces philosophes, notamment ceux de devenir, d'agencement et de ritournelle. Leur emploi est cependant plutôt mis en fonctionnement qu'argumenté. Le lecteur intéressé se référera avec profit aux livres de ces auteurs, notamment à Mille Plateaux (Deleuze et Guattari, 1980). 26. Pas d'une musique de sorcière, mais d'une musique qui est elle-même sorcière. 
Quelques traits d'écriture qui illustrent, sans l'épuiser, cette diversité : le registre aigu sans cesse sollicité chez tous les instruments, les glissandi en trémolo du violoncelle, les variations perpétuelles de timbres: sul ponticello, arco, pizzicatto normal ou battuto, harmoniques ascendantes en quadruples croches, sans compter les innombrables changements de rythme, de vitesse et de nuance.

Devenir-nuit, car tout y est murmuré, esquissé, évoqué. Ici les notes ne pèsent pas le poids de la forte expérience terrestre, au contraire, les notes ne pèsent pas du tout, ne veulent pas avoir de poids et tournent le dos au jour aveuglant, comme Tristan: O diese Sonne (Wagner, 1973, acte III, $2^{e}$ scène). Devenir-nuit, c'est construire un rapport à la disparition, au murmure, au désir, en évitant les appuis des foulées pesantes, l'insistance démonstrative et la clarté du jour. La musique pour la nuit n'a plus rien à voir avec l'Histoire et l'État, comme aurait pu le dire Deleuze.

Devenir-imperceptible, car ce qui disparaît aux abords du ressouvenir, ce qui nous échappe lorsqu'on tente de le saisir, ce sont des réminiscences des autres quatuors, des lambeaux de mémoire. Ainsi les motifs vont-ils s'accumuler au point d'échapper à la perception dans leurs nouveaux agencements. Tout devient évanescent.

Devenir-imperceptible, comme ce fragment de Waves (Deuxième Quatuor) qui, dès le début, revient sans qu'on le reconnaisse vraiment tout à fait (fig. 28). Et tout s'ensuivra de même avec d'innombrables références aux quatuors précédents, à tel point que le Sixième Quatuor ne contiendra presque aucune note de musique qui ne soit déjà présente dans les Quatuors nos 1 à 5 .

Figure 28

Sixième Quatuor, page 2, $3^{\text {e }}$ système

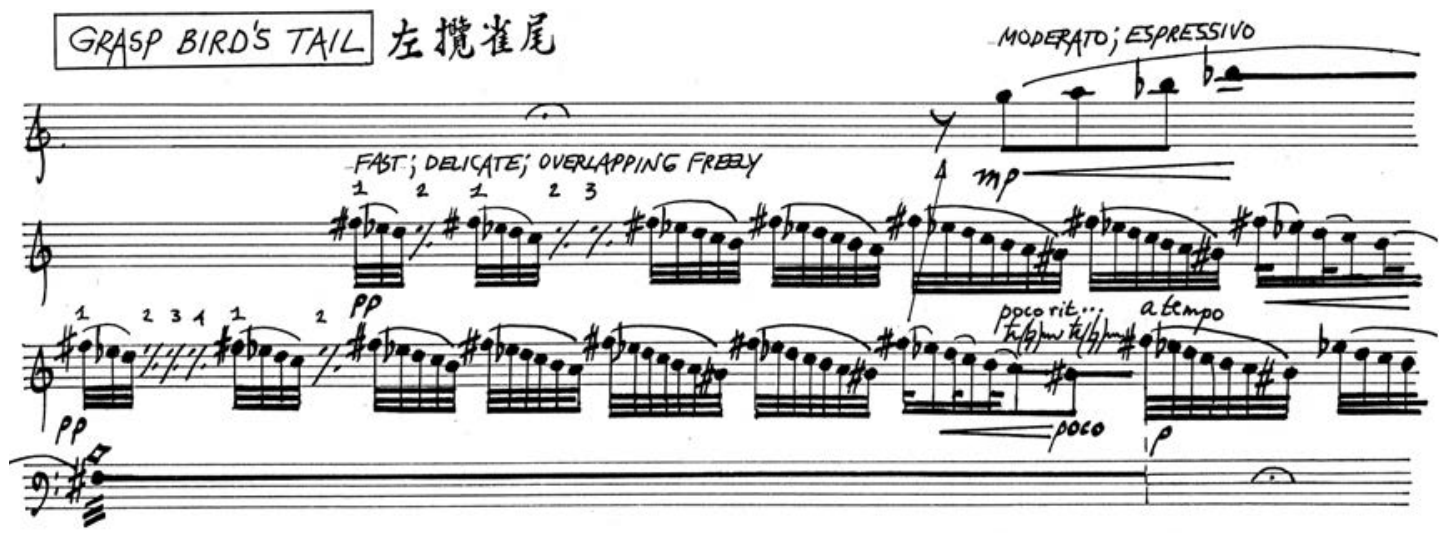

Le devenir-imperceptible, c'est aussi la non-permanence de toutes choses, thème héraclitéen ici encore. Si Schafer revient en effet sans cesse dans les tra- 
ces des cinq quatuors précédents, il parvient malgré tout à conserver une individualité propre au Sixième Quatuor. Non seulement les motifs, les timbres et les pulsations migrent-ils d'un quatuor à l'autre, mais encore faut-il souligner que les autocitations ne sont jamais narcissiques; ce sont plutôt des traces qui sont rendues quasi imperceptibles dans leurs nouveaux agencements. Le compositeur n'insiste pas sur les ressemblances de ces rappels, au contraire serions-nous tentés d'ajouter, il triture son ancien matériau sans vergogne.

Dans l'épisode qui suit, les quatre instrumentistes jouent simultanément des passages tirés de cinq quatuors différents (fig. 29)!

Figure 29

Sixième Quatuor, page 18, $1^{\text {er }}$ système

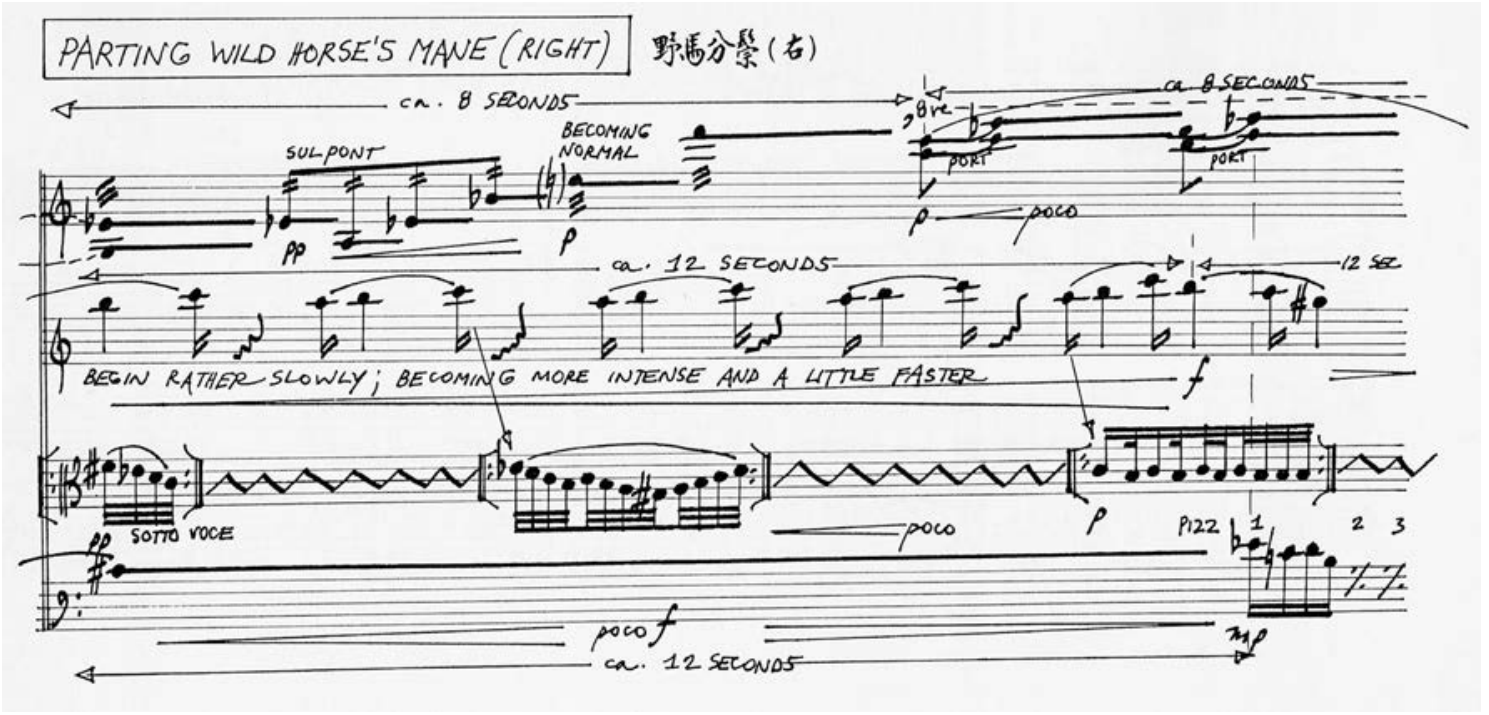

Dans ce passage (fig. 29), le premier violon présente le thème du loup du Cinquième Quatuor et un motif en tierces tiré du Troisième Quatuor, le second violon, l'alto et le violoncelle évoquent simultanément trois passages distincts de Waves (Deuxième Quatuor) et les pizzicati du violoncelle sont tirés du Quatrième Quatuor. Enfin, le dernier motif joué par l'alto dans ce passage est tiré du Premier Quatuor. Ainsi, en écoutant le Sixième Quatuor, nous entrons et nous n'entrons pas dans le même fleuve.

Devenir-imperceptible, c'est encore, de l'aveu même de Schafer, cette recherche de l'impossible équilibre entre les forces actives (yang) et passives (yin). Les doubles et les contraires réapparaissent donc sans relâche dans cette musique. Devenir-imperceptible dans la durée aussi, en raison de l'extrême fragmentation des épisodes, agencés par des transitions qui sont parfois des sortes d'avancées et de désintégrations presque simultanées (fig. 30). 
Figure 30

Sixième Quatuor, page 23, $1^{\text {er }}$ système

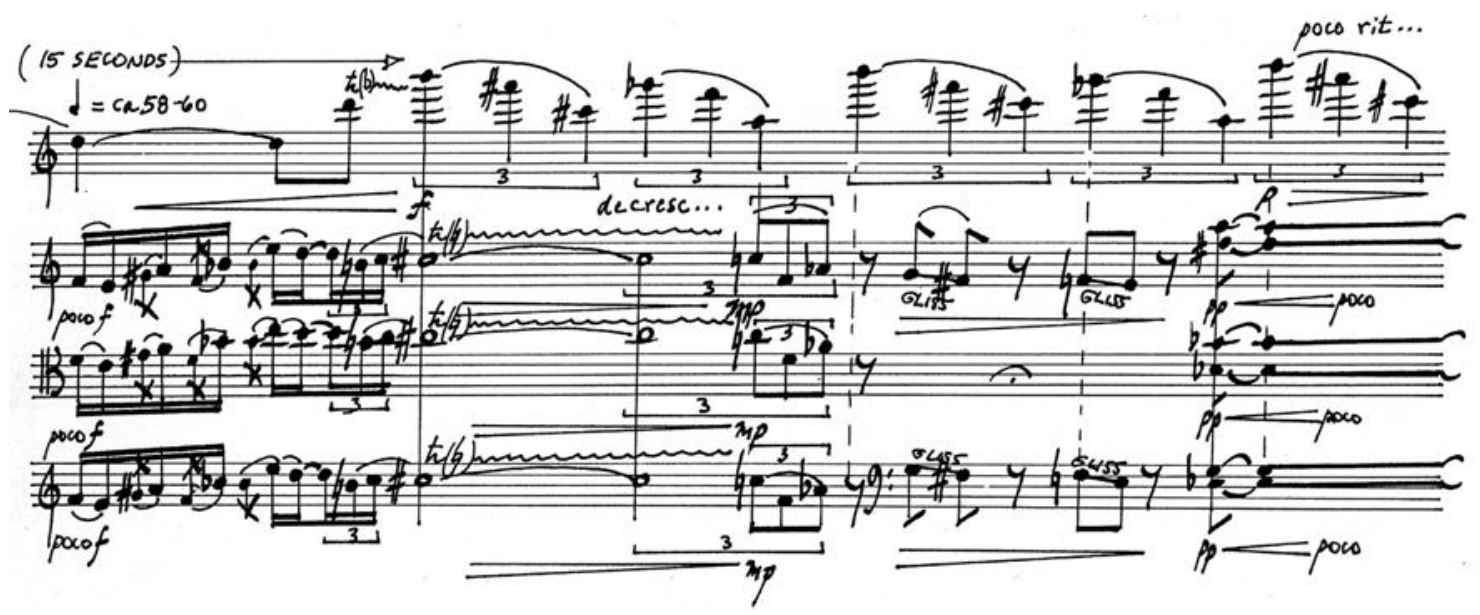

Devenir-animal, car la musique y est geste et mouvement du corps. Tout comme la séquence des 108 mouvements de Taï Chi qui en forme les canalisations, les réseaux cachés, les rhizomes. Selon les voux du compositeur, l'œuvre peut être interprétée avec ou sans la participation d'un Taï Chi'iste exécutant les mouvements de gymnastique chinoise en synchronisation avec la musique. II n'y a cependant pas de redondance entre l'intensité sonore de la musique de Schafer et ce que I'on peut voir des mouvements du Taï Chi'iste. Par exemple, une grande énergie musicale peut correspondre à une retenue physique extrême. Ces mouvements sont l'animation de la musique: tensions physiques parfois fortes dans des mouvements lentissimes, tensions sonores toujours en mouvement, concentrées et évolutives. Flexibilité et souplesse dans les mouvements de Taï Chi comme dans la musique.

Devenir-animal d'une autre manière aussi, car les mouvements de Taï Chi ramènent l'homme à sa corporéité, le rivent à l'espace qu'il crée de ses gestes. Car il y a le geste physique que l'on vit en intériorisant le mouvement de l'autre et il y a le corps que l'on voit dans les ombres bleutées de la nuit ${ }^{27}$. Le Sixième Quatuor, c'est aussi l'intimité du couple révélée par le compositeur: un homme qui regarde sa femme faire sa séquence d'exercices de Taï Chi (Schafer, 1993, page frontispice). Les charmes secrets sont évoqués mais nulle part décrits. L'extrême fluidité de la musique rappelle ça et là les Deuxième et Cinquième Quatuors.

Et puis il y a ce devenir-ritournelle, car la partition est, on l'a vu, le creuset d'incessants retours sur des motifs et des bribes des quatuors précédents. Comme de petites musiques que l'on se chante intérieurement et dont on ne peut plus se défaire pendant des jours (Reik, 1953). La page 20 de la partition (fig. 31 ) comporte une ritournelle assez orientale, d'un climat de danse élégante et ensorcelante, qui paraît neuve mais qui est en fait issue de motifs du Quatrième Quatuor.

27. Notons qu'à la salle Pierre-Mercure, en décembre 1999, lors de la première intégrale en concert des sept quatuors réalisée par le Quatuor Molinari, Murray Schafer et Guido Molinari s'étaient mis d'accord pour présenter le Sixième Quatuor sur fond d'un des vastes Quantificateurs bleus de Molinari. 
Figure 31

Sixième Quatuor, page 20, $2^{\text {e }}$ système

王女穿梭(右)

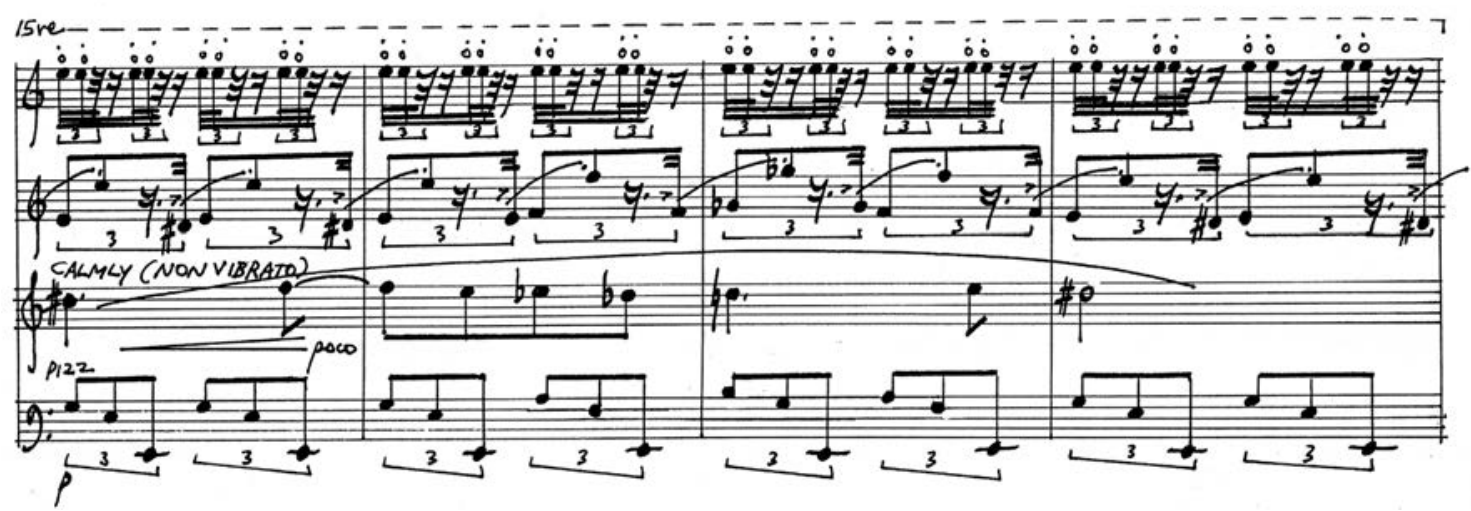

Il y a aussi ce motif rythmique obsédant appelé Ward Off Monkey (du nom d'un des mouvements de Taï Chil, qui est à la fois une ritournelle et un deveniranimal (fig. 32). Ce motif prendra un relief particulier dans le Septième Quatuor, avec l'apparition du personnage de Tapio, joué par le violoncelliste dans cette dernière œuvre.

Figure 32

Sixième Quatuor, page 24, $1^{\text {er }}$ système

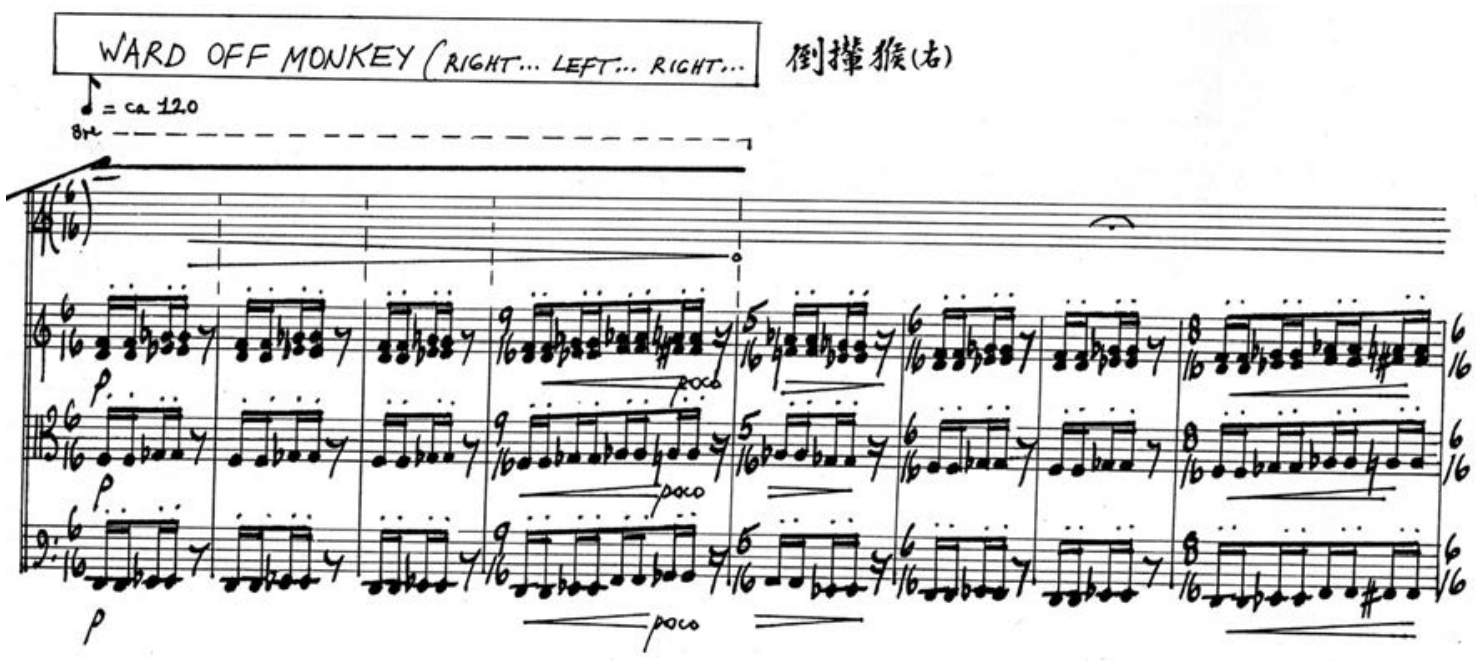


Devenir-animal, encore et toujours. Les doubles sont maintenant des multiplicités au sens deleuzien du terme. Dans un autre passage (fig. 33), on ne sait plus bien s'il s'agit d'un devenir-cheval ou d'un devenir-insecte...

Figure 33

Sixième Quatuor, page 16, 1 ${ }^{\text {er }}$ système

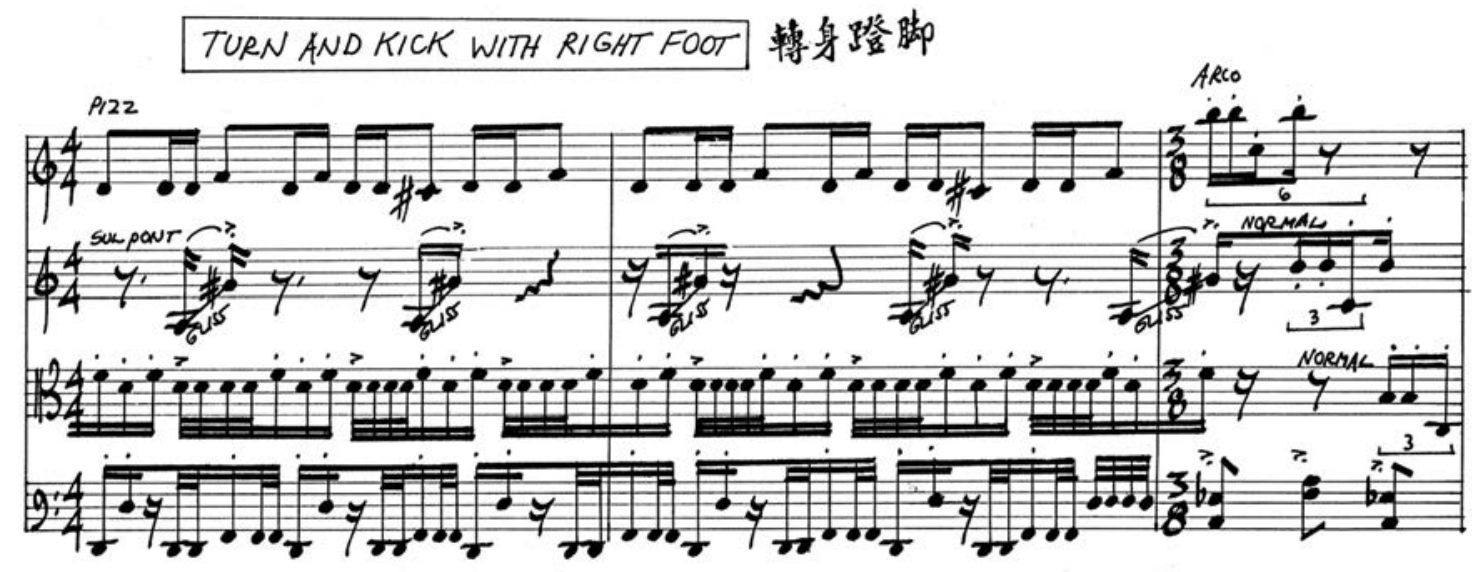

Et toute la musique s'ensuit de même, sans mode discursif, mais plutôt par des agencements fugaces comme ceux qui ferment l'œuvre (fig. 34, p. 44), dans un pur défilement de sonorités dont le montage nous prend et nous captive par la magie des motifs évanescents et murmurés. Devenir-nuit!

\section{Septième Quatuor (1998) avec soprano obligé ${ }^{28}$}

Nous veillons dormants et veillants dormons. Je ne vois pas si clair dans le sommeil ; mais, quant au veiller, je ne le trouve jamais assez pur et sans nuage.

MONTAIGNE

Celui qui dort est tous les hommes.

BORGĖS

Lorsque commence le Septième Quatuor, après les phrases introductives ramenant des sources que l'on reconnaît (motif d'ouverture repris de la fin du Sixième Quatuor [supra, fig. 34], motif d'Ariane [supra, fig. 22, 28 et 34]), le monde de la nuit, du rêve, du cauchemar et de la folie fait son entrée. Unissons à distance,
28. Composé à Indian River, en Ontario, et terminé le 15 décembre 1998, le Septième Quatuor a été commandé par le Quatuor Molinari avec l'aide de Radio-Canada (Montréal), de la Canadian Broadcasting Corporation (Toronto) et du Conseil des Arts du Canada. L'œuvre fut créée en version concert par le Quatuor Molinari et la soprano Nathalie Paulin, à Ottawa, le 4 mai 1999. La création en version scénique fut ultérieurement réalisée par le Quatuor Molinari et la soprano MarieDanielle Parent, à Montréal, le 11 décembre 1999. 
Figure 34

Sixième Quatuor, pages 32-33, 3 systèmes successifs
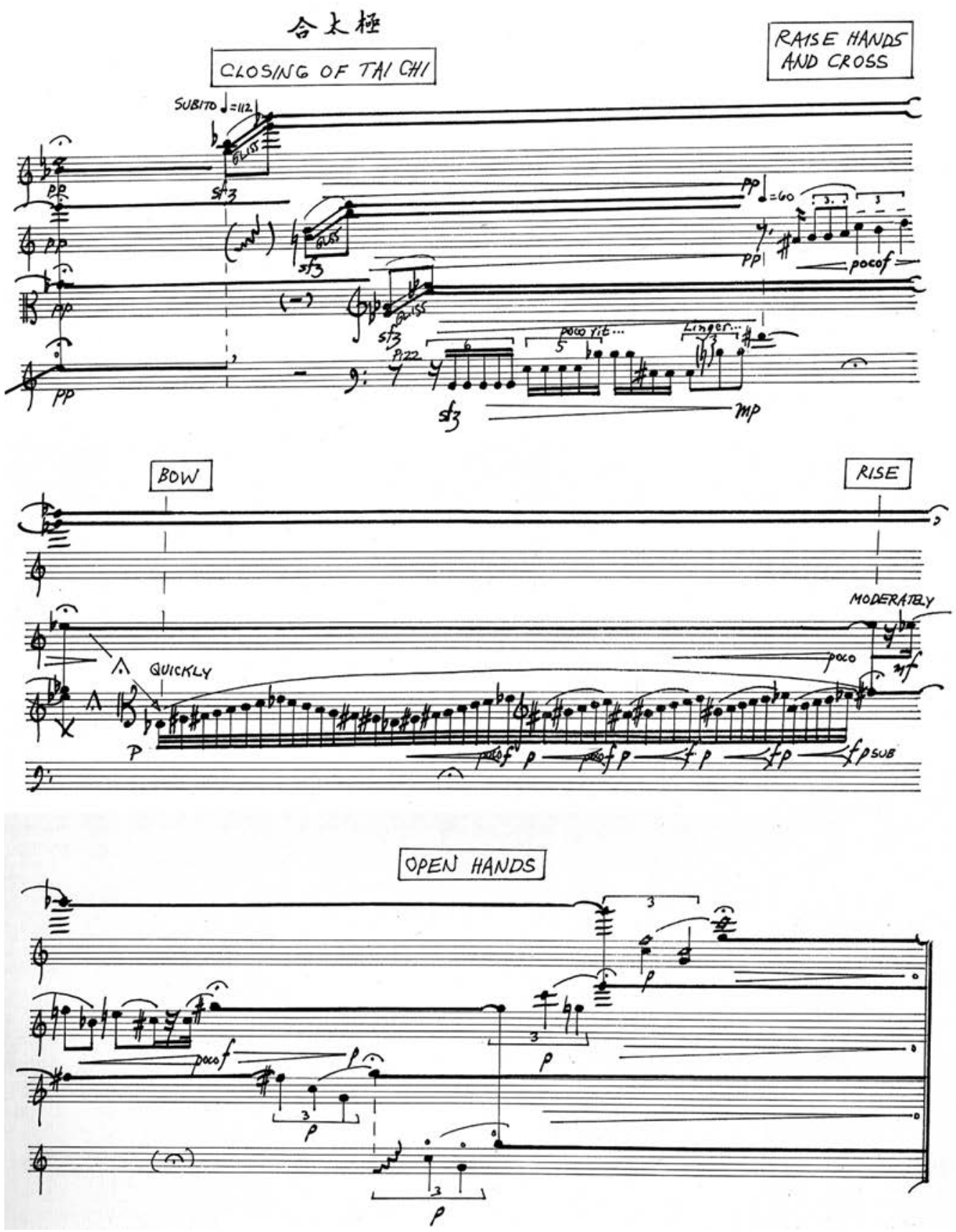
décalages progressifs, flammes rouges, jaunes et bleues. Soprano schizophrène en camisole de force, instrumentistes du quatuor habillés de couleurs vives ${ }^{29}$, tout concourt à établir un climat à la foi onirique et fou.

La soprano, hallucinée, viendra plusieurs fois interrompre le quatuor à cordes. Avec un naturel aussi déconcertant que vrai, on plonge de la chambre privée à l'opéra public, en abolissant la distance qui sépare les deux genres. Comme au siècle dernier E. T. A. Hoffmann et Robert Schumann, Schafer s'amuse encore et toujours de sa faculté de dédoublement. Dans une complète démesure, il fait coïncider un univers de délire psychologique avec un univers de sonorités tournoyantes et spatialisées, aux allures de fantastique.

Car il s'agit bien, ici encore, d'un imaginaire romantique. Dans le Septième Quatuor, les éléments de base de la nature romantique sont présents : la forêt, les elfes, la nuit, les ombres, la folie, l'étrangeté et l'inquiétude ${ }^{30}$. La curieuse alliance de tendresse et d'ironie qu'on y retrouve aussi achève de convaincre du caractère romantique de l'œuvre. Pourtant les personnages comme la schizophrène soprano ou l'animal Tapio, qui joue du violoncelle en marchant ${ }^{31}$, pourraient bien être ceux de Beckett ou du Finnegans Wake de Joyce. C'est donc d'un néoromantisme qu'il s'agit, d'un romantisme assumant le XXe siècle.

Le Septième Quatuor est chargé de péripéties invraisemblables, d'intermèdes et de digressions. Le personnage de la chanteuse est pathétique: tantôt ricanante, tantôt implorante, mais toujours sincère dans ses exigences et ses questions.

Du point de vue du genre, il n'est plus certain pourtant qu'il s'agisse là d'un quatuor à cordes. D'abord parce que la soprano prend une place importante qui, malgré son caractère épisodique, est beaucoup plus intimement liée à l'ensemble de l'œuvre que ce n'était le cas dans le Second Quatuor de Schönberg, emblême de cette combinaison vocale et instrumentale. Mais aussi parce que les musiciens jouent à partir de différents endroits de la salle et des coulisses et qu'ils ne se retrouvent en formation habituelle de quatuor que dans les ultimes moments de l'œuvre. Ces déplacements scéniques, nombreux comme jamais auparavant dans un quatuor de Schafer, ne sont pas seulement des innovations techniques qui permettent une circulation très impressionnante des sons dans la salle de concert, mais ils répondent aussi aux nécessités poétiques et dramatiques du texte chanté, récité et crié par la schizophrène.

Dans le Septième Quatuor, il y a opposition permanente entre l'écriture pour les cordes, dramatique, acérée et accélérée, et l'écriture pour la voix humaine, plus lente et plus lyrique, exprimée en demi-teintes rêveuses et qui contient étonnamment de rares moments d'hystérie. Cependant, lorsque la folie sauvage du soprano se déverse, celle-ci devient communicative pour les autres, comme dans ce passage où s'enchevêtrent les gammes des cordes et le vibrato délirant de la soprano (fig. 35).
29. Rouge pour le premier violon, bleu pour le deuxième, jaune pour l'alto et un costume d'elfe vert pour le violoncelle, incarnation d'un personnage appelé Tapio et qui fait référence aux légendes finlandaises du Kalevala.

30. On pense, entre autres, à Jean-Paul Richter, à E. T. A. Hoffmann, à Schumann et à Mahler.

31. Un harnais, fabriqué par Dany Zen pour le Quatuor Molinari, a permis cette innovation importante. 
Figure 35

Septième Quatuor, page 16, $2^{\mathrm{e}}$ système

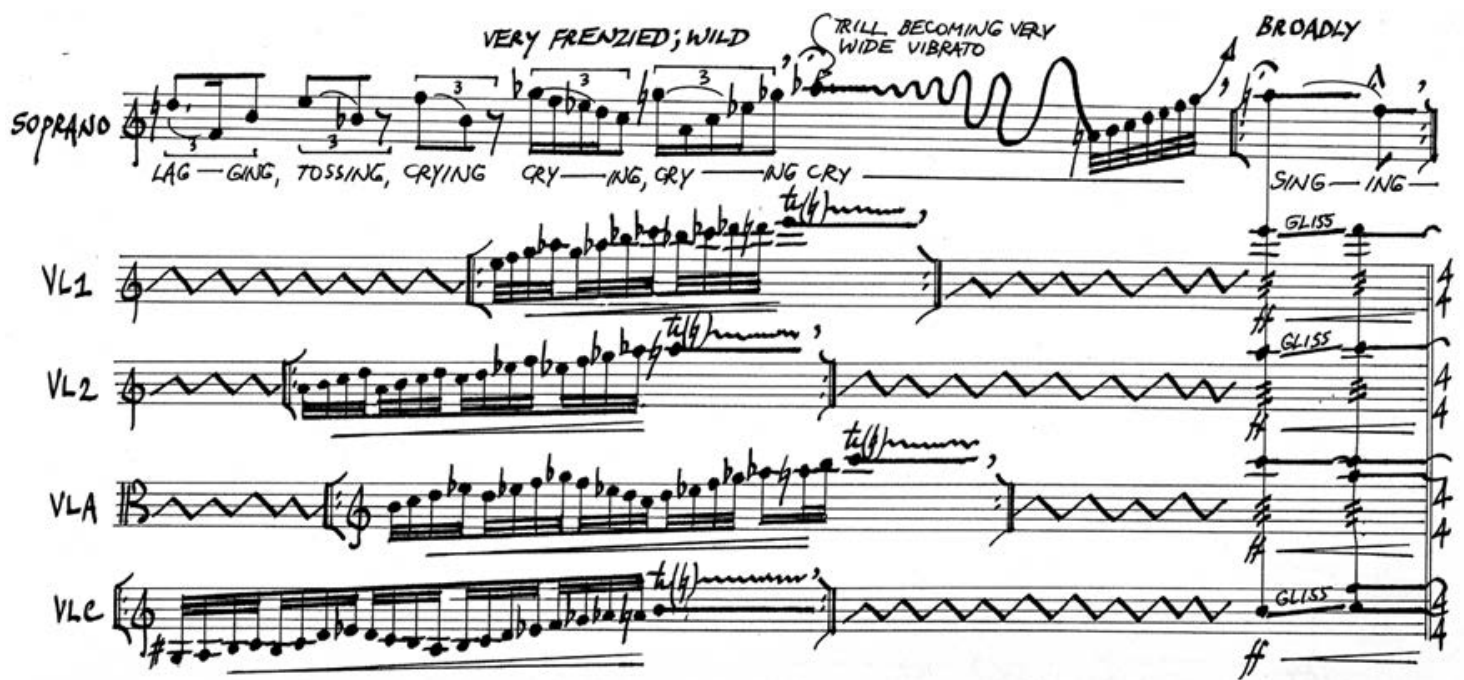

Ces caractéristiques ne sont pas l'expression de personnalités, ni ne sont des signatures musicales. Car si le rouge du premier violon est dès le début marqué du motif d'Ariane en dissonances qui s'amplifient à chaque reprise en cascades virtuoses descendantes (fig. 36), il reviendra en revanche plusieurs fois à l'alto et au second violon, mais jamais au violoncelle Tapio, l'esprit de la forêt.

Figure 36

Septième Quatuor, page 3, $1^{\text {er }}$ système

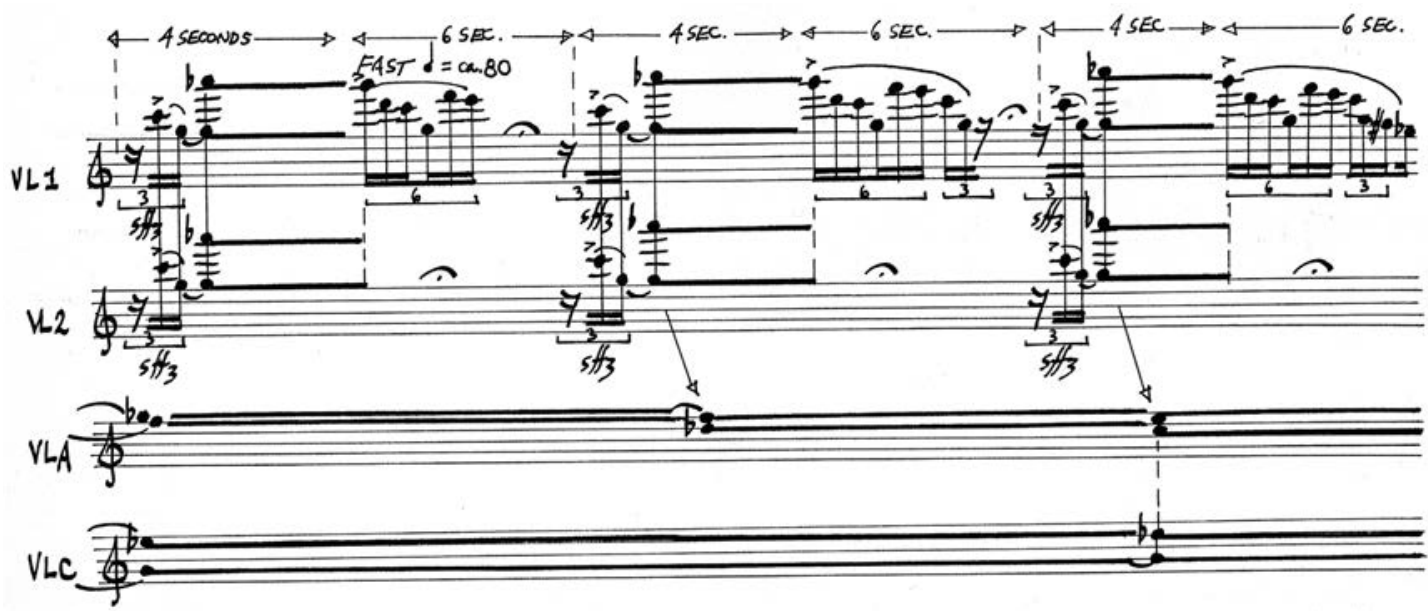


L'inquiétude de Tapio (le violoncelle) est souvent prémonitoire des moments de délire collectif du quatuor. Ainsi, le passage qui reprend le motif rythmique Ward Off Monkey du Sixième Quatuor (fig. 32) entraîne-t-il de brutaux accords de l'alto et des glissandi suraigus des violons, d'une terreur certaine (fig. 37).

Figure 37

Septième Quatuor, page 19, $3^{e}$ système

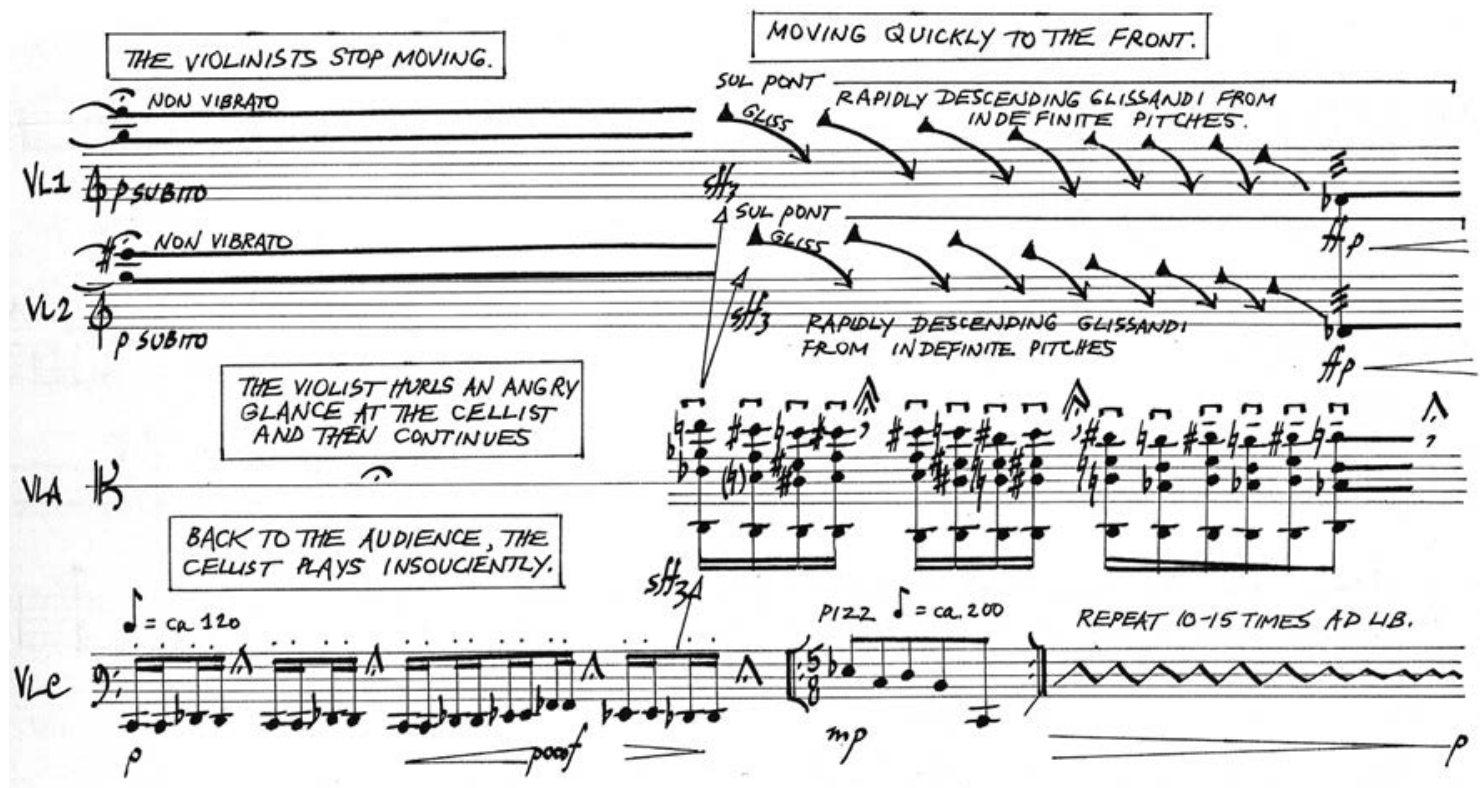

De la nuit surgit le spectre dément de la soprano avec ses souvenirs et ses inquiétudes qui sont très loin du monde domestiqué et structuré du jour:

\author{
If you and I were music... real music... \\ I could explain. \\ But we must wait for that, I mean the music... \\ when each note is weighed \\ when emotions are expressed carefully by contrapuntal - however \\ in the meantime just an ordinary thanks. \\ By the way I like your nose ${ }^{32}$.
}

Opéra de chambre, le Septième Quatuor l'est sans doute. Mais la soprano n'est cependant pas une diva réelle, elle est plutôt une aliénée de cauchemar aussi inspirée dans ses éclairs lyriques qu'elle peut être vulgaire par moments. Pervertie, la musique trahit ailleurs l'identité trouble de cette folle poétesse et l'instabilité qu'elle crée au sein du quatuor (fig. 38).
32. Textes d'une femme schizophrène, tirés de la collection de Miss Marion Kalkmann, directrice du nursing de la clinique neuropsychiatrique de l'Université de l'Illinois. (Moholy-Nagy, 1947, p. 323.) 
Figure 38

Septième Quatuor, page 22, $1^{\text {er }}$ système

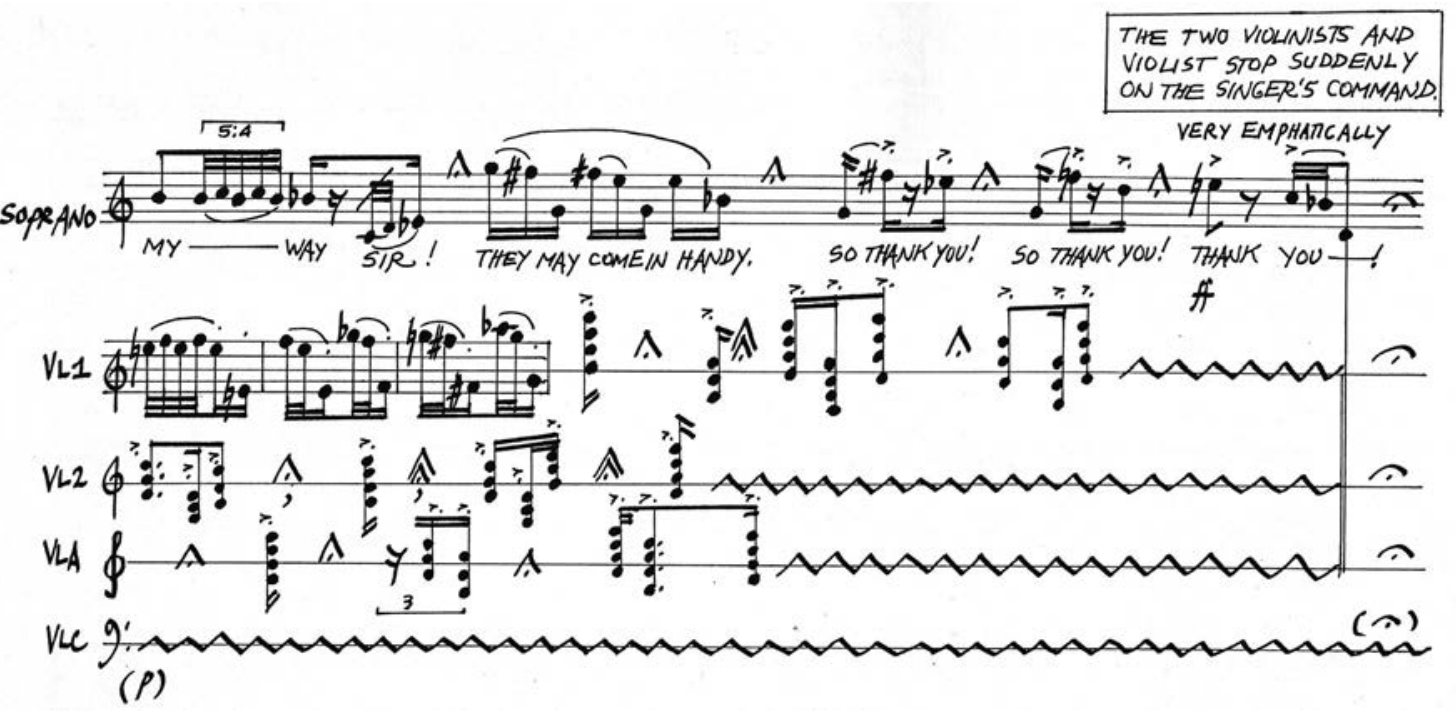

La folie déployée n'est pourtant jamais un simulacre de folie, elle en prend au contraire la substance. On sent bien que Schafer ne souhaite pas prendre un recul clinique vis-à-vis de cette folie, il y puise au contraire ses racines. La fantaisie débridée de la musique est à l'image des mots de la schizophrène, elle reconstruit l'univers du rêve, de la nuit, du délire, de la solitude et de la mort.

Cette folie n'est pourtant pas d'une complète irrationalité, car la schizophrène a aussi ses moments visionnaires et critiques du mouvement du monde.
It wouldn't have been the same if you had analyzed
It wouldn't have been the same if you had criticized
It wouldn't have been the same if you and I
had our noses in the earth.

Sans linéarité, le texte est plutôt parole que discours. Les soupirs des instruments, les silences fréquents, le caractère méditatif et intérieur de la musique qui suit les disparitions successives de la chanteuse sont, à ce titre, fort éloquents. Ainsi, après le premier départ de la soprano, le violoncelle attaque une cadence sombre et grave (fig. 39). 
Figure 39

Septième Quatuor, page 10, $3^{e}$ et $4^{\mathrm{e}}$ systèmes
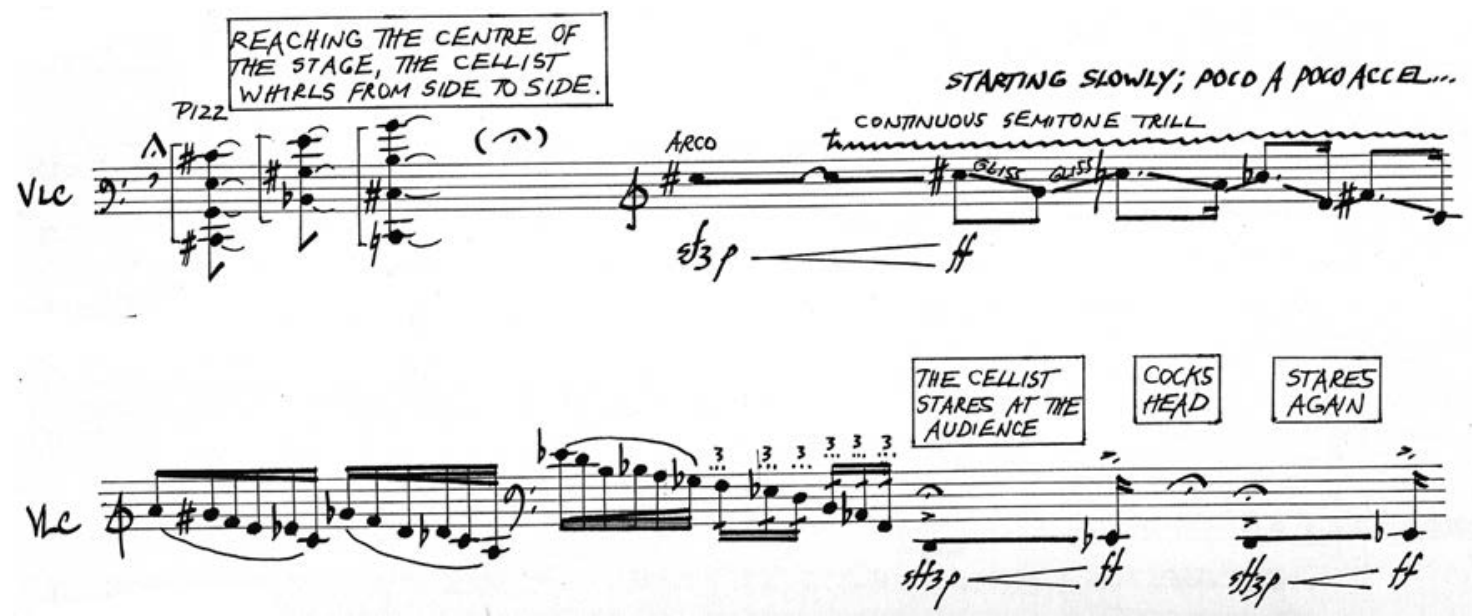

Après que la soprano quitte une seconde fois la scène, les instrumentistes tentent de retrouver un son d'ensemble par d'extatiques unissons... joués à distance

(fig. 40).

Figure 40

Septième Quatuor, page $17,2^{e}$ et $3^{e}$ systèmes

L VERY FAST; GHOST LIKE; AKL INSTRUMENTS N UNISON
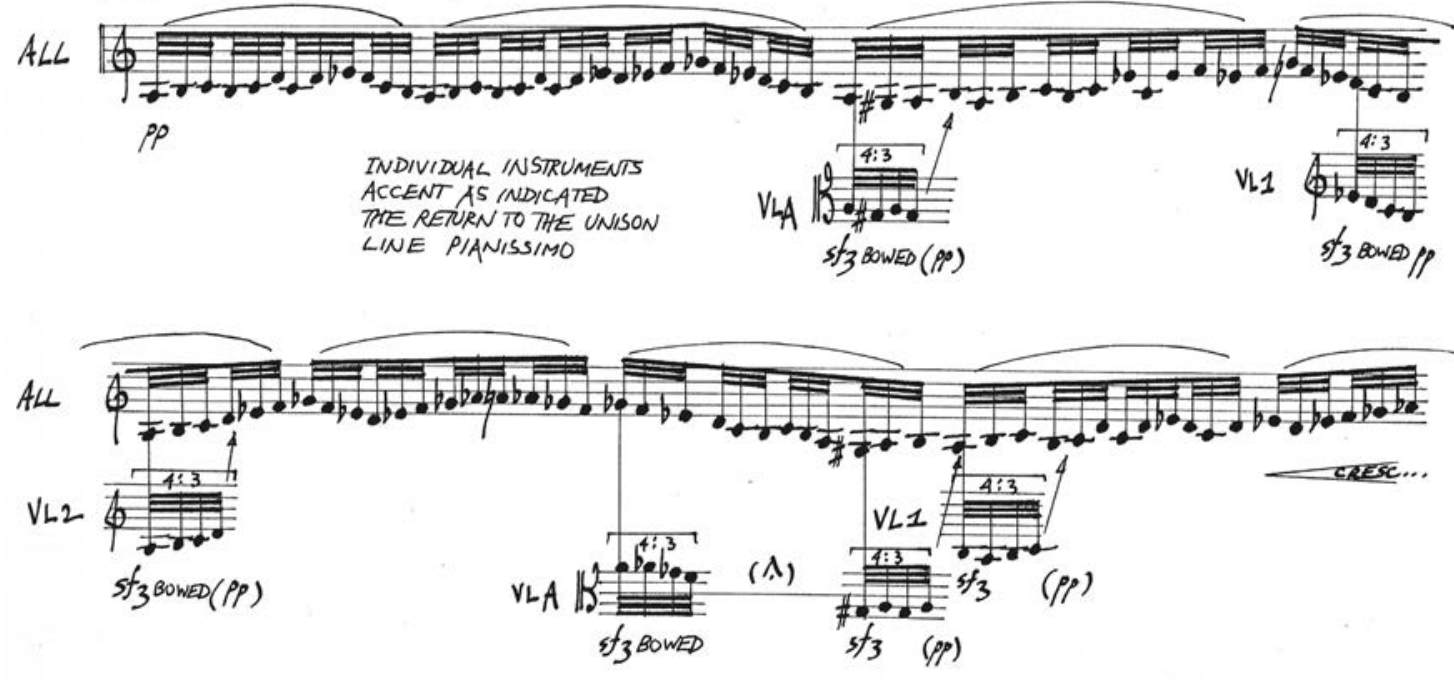
Au troisième départ, la musique est une brève lamentation du violoncelle, aussitôt détruite par les pitreries de l'alto et du deuxième violon qui surgissent comme des lutins féroces et souriants au son cadencé des wood-blocks (fig. 41)!

Figure 41

Septième Quatuor, page $25,3^{\mathrm{e}}$ et $4^{\mathrm{e}}$ systèmes

$R$ SLOW' BEWITCHING; WITHA SLIGHT PORTAMENTO BETWEEN NOTES
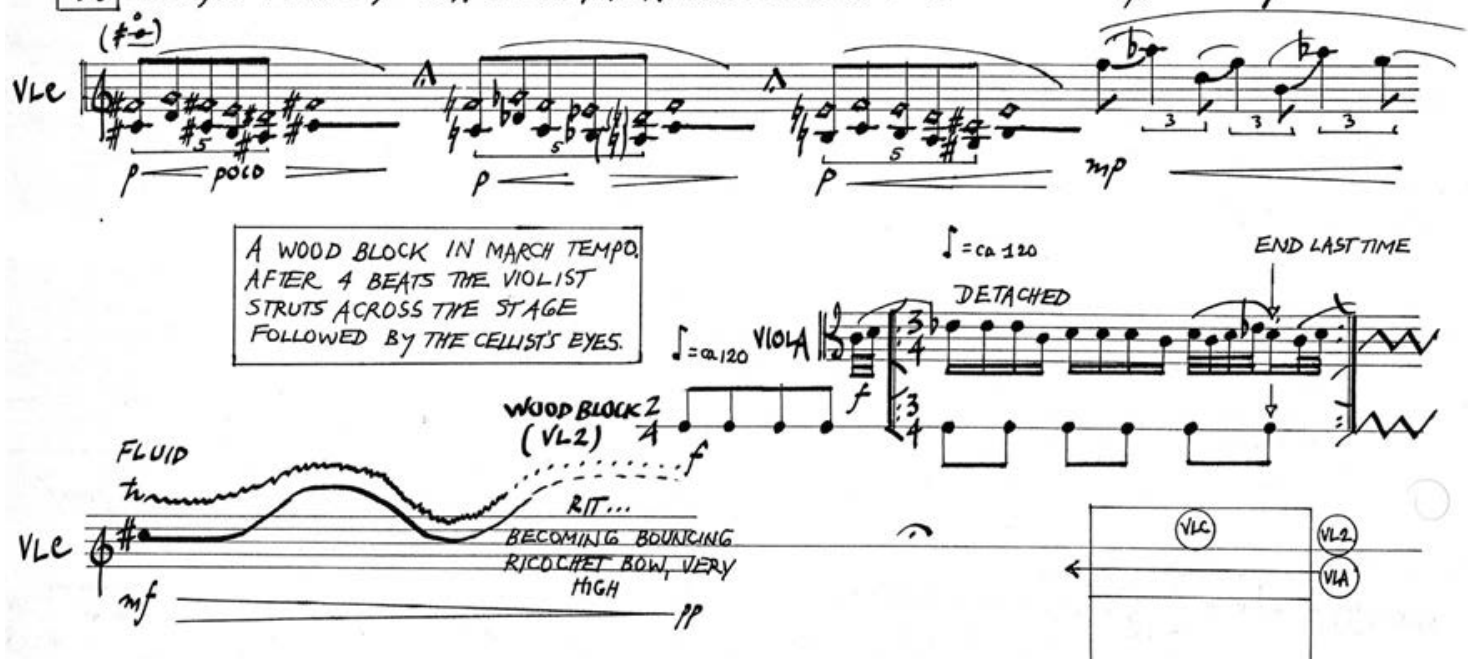

Comme Mahler ou Chostakovitch, qui pervertissent volontairement d'éclats de rires sardoniques les moments d'intense peine, Schafer place le drame existentiel de cette schizophrène dans un lieu hostile, compte tenu de la poésie de ses questions et de la tendresse de ses paroles. C'est comme si l'alto, puis le second violon, se réjouissaient avec sarcasme de son départ.

Lorsqu'à la fin de l'œuvre, la soprano réclame à grands cris pleins de grotesques vibratos, et jusqu'à l'extinction que produit son éloignement progressif : I want music. I want to sing, sing, sing, sing, sing, sing, sing, sing, sing..., on trouve réunis sur scène pour un unique moment les quatre musiciens du quatuor. Aux glissandi dépressifs à l'unisson du trio répondent les envolées enjouées du violon rouge. On passe alors sans ménagement de la détresse à l'émerveillement et l'on se dit que parfois les rêves font réellement la folie.

Ainsi se termine ce parcours dans l'œuvre pour quatuor à cordes de R. Murray Schafer, parcours qui demeure ouvert puisque le cycle se poursuivra au moins dans le Huitième Quatuor ${ }^{33}$. Mais nous voudrions souligner que comme toute proposition de parcours, le nôtre souhaite conserver la possibilité de retours réflexifs et d'exploration de nouvelles avenues de lecture de ces œuvres aussi sin-

33. La création en est prévue par le Quatuor Molinari au mois d'août 2001, dans le cadre du Festival de Stratford. cères qu'enrichissantes pour ceux et celles qui choisissent d'en suivre la trace. 


\section{Bibliographie}

ADORNO, T. W. (1976), Mahler, une physionomie musicale, Paris, Éditions de Minuit, $266 \mathrm{p}$.

BECKETT, S. (1978), Poèmes, suivi de "Mirlitonnades", Paris, Éditions de Minuit, 44 p. BOLLACK, J. et WISMAN, H. (1972), Héraclite ou la séparation, Paris, Éditions de Minuit, $405 \mathrm{p}$.

BORGÈS, J. L. (1981), Le Chiffre, Paris, Gallimard, 145 p.

DEleuZE, G. et GUATTARI, F. (1980), Mille Plateaux, Paris, Éditions de Minuit, 645 p.

DUFRENNE, M. (1995), «Le Style», Encyclopaedia Universalis, Paris, t. 21 ,

p. 695-698.

GRANDBOIS, A. (1990), Poésies, Montréal, Presses de l'Université de Montréal, 2 †.

HALBREICH, H. (1986), Les Six Quatuors de Bartók, Quatuor Végh. Astrée Auvidis, E 7717-7719. Notices de l'enregistrement sur disques compacts (14 pages).

JAMEUX, D. (1980), Alban Berg, Paris, Seuil, coll. «Points», 191 p.

JOYCE, J. (1939), Finnegans Wake, New York, Viking Press, 628 p.

KERMAN, J. (1982), The Beethoven Quartets, Westport, Greenwood Press, 386 p.

MAHLER, G. (1975) [1894], Symphonie no 2 en do mineur, Londres, Universal Edition, 209 p. Partition miniature, U.E.2933.

MOHOLY-NAGY, L. (1947), Vision in motion, Chicago, Theobald Editions, 371 p. MONTAIGNE, M. de (1962), OEuvres complètes, Paris, Gallimard, "La Pléiade», $1791 \mathrm{p}$.

NOVALIS (1943), Hymnen an die Nacht, Geistliche Lieder, trad. par G. Bianquis, Paris, Aubier, $186 \mathrm{p}$.

REIK, T. (1953), The Haunting Melody: Psychoanalytic Experiences in Life and Music, New York, Da Capo Press, 38 p.

ROSSET, C. (1983), La force majeure, Paris, Éditions de Minuit, 105 p.

SAMUEL, C. (1967), Entretiens avec Olivier Messiaen, Paris, P. Belfond, 236 p.

SCHAFER, R. M. (1970), String Quartet [n 1], Vienne, Universal Edition, 15 p. Partition 15546.

— (1975), E. T. A. Hoffmann and music, Toronto, University of Toronto Press, 202 p. 
— (1976), Waves, String Quartet n 2, Indian River, Ontario, Arcana Edition, 20 p. Partition.

- (1980), Adieu Robert Schumann, Vienne, Universal Edition, 59 p. Partition.

- (1980), String Quartet n 3, Indian River, Ontario, Arcana Edition, 26 p. Partition.

- (1989), String Quartet n 4, Indian River, Ontario, Arcana Edition, 30 p. Partition.

- (1989), Rosalind, String Quartet n 5, Indian River, Ontario, Arcana Edition, 23 p. Partition.

_- (1993), Parting Wild Horse's Mane, String Quartet n 6, Indian River, Ontario, Arcana Edition, 33 p. Partition.

- (1998), String Quartet $n^{\circ} 7$ with obligato soprano, Indian River, Ontario, Arcana Edition, 38 p. Partition.

STRAVINSKY, I. (1962), Chroniques de ma vie, Paris, Denoël, 201 p.

TAKEMITSU, T. (1996), Toki no Entei (Gardener of Time), Tokyo, Shincho Sha, 219 p. Livre posthume.

WAGNER, R. (1973), Tristan und Isolde, New York, Dover, 655 p. Partition miniature.

XENAKIS, I. (1971), Musique, architecture, Paris, Casterman, 160 p. 


$$
\text { sa }
$$




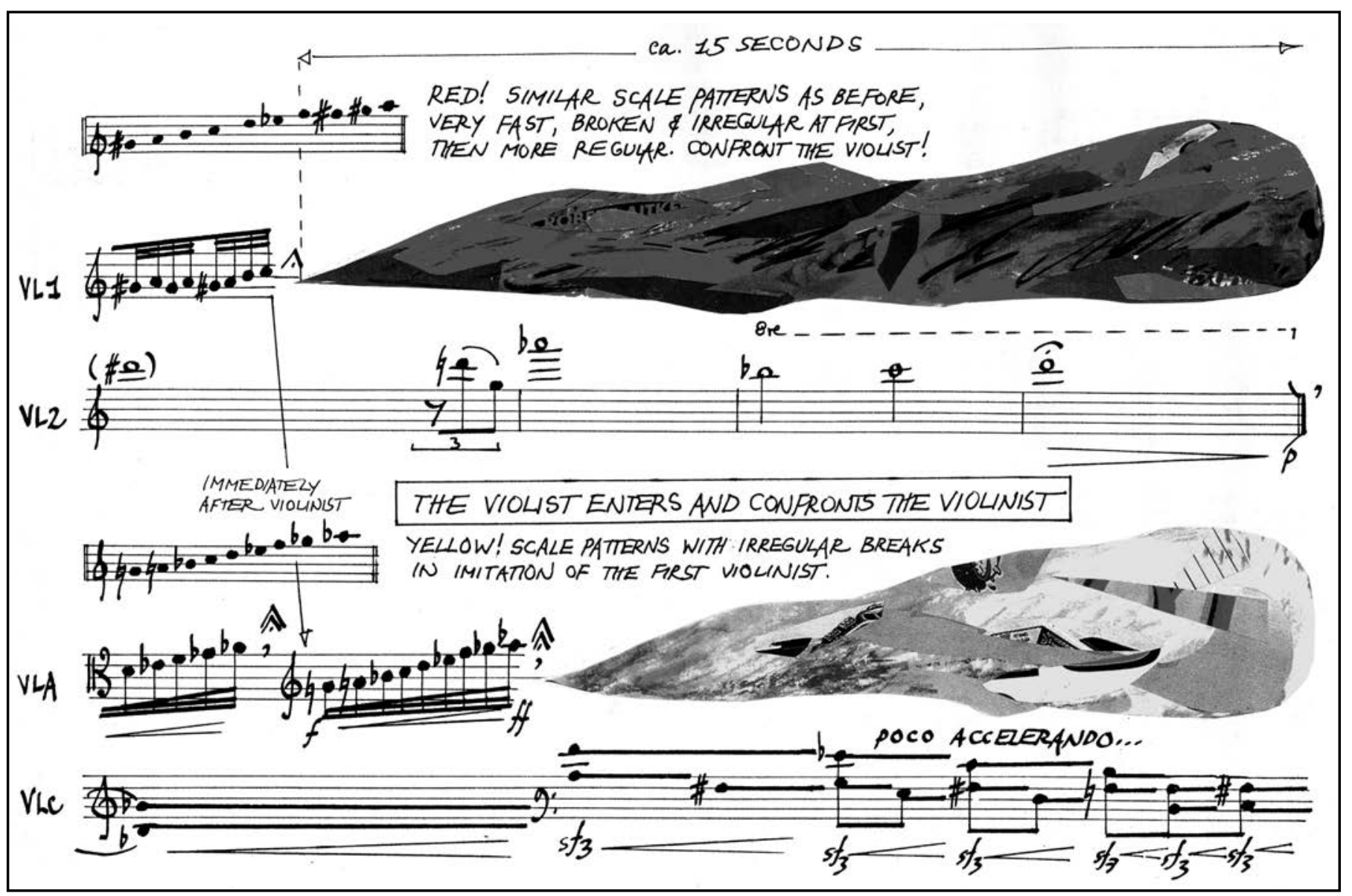

